\author{
Manuel Naveiro \\ Manuel Romero Gómez \\ Ignacio Arias Fernández \\ Javier Romero Gómez
}

http://dx.doi.org/10.21278/brod72404

ISSN 0007-215X

eISSN $1845-5859$

\title{
EXPLOITATION OF LIQUEFIED NATURAL GAS COLD ENERGY IN FLOATING STORAGE REGASIFICATION UNITS
}

UDC 669.91-026.73:629.51

Review paper

\begin{abstract}
Summary
This paper aims to review regasification technology installed in Floating Storage Regasification Units (FSRUs) and the potential offered by the exploitation of cold energy from liquefied natural gas (LNG) in these vessels. The assessment describes the main characteristics of regasification systems along with their respective advantages and limitations. Regasification systems in direct exchange (seawater and steam) and systems with intermediate fluids that use propane or water-glycol in the heat transfer process are studied. In recent years, water-glycol systems have cornered the market. The mixture, besides reducing the risk of freezing, is nonflammable, economical and highly available. Thermodynamic analysis of the regasification process shows that LNG cold energy is the main source of residual energy in these vessels; the specific energy and exergy content is more than double that of engine exhaust gases. Exploitation of this cold energy in power cycles could significantly reduce FSRUs harmful emissions and electrical energy could even be exported to shore. The organic Rankine cycle technology is the most well-known and widely studied, although scientific literature is scarce and there is a need to propose new regasification systems with cold energy exploitation that can be adopted on these vessels.
\end{abstract}

Key words: $\quad$ Floating Storage Regasification Unit; liquefied natural gas; regasification system; cold energy

\section{Introduction}

Energy demand grew on average $1.28 \%$ per annum throughout the $2010-2019$ period [1]. However, the Covid-19 pandemic has stifled developments in the energy field, causing an even more unpredictable future. The International Energy Agency (IEA) [2] assesses that in 2020 energy demand will fall by $5 \%, \mathrm{CO}_{2}$ emissions by $7 \%$ and energy investment by $18 \%$. With regard to fossil fuels, natural gas (NG) has been the least hit by the pandemic and remains the non-renewable energy source with best prospects. The Stated Policies Scenario of the World Energy Outlook 2020 [1] forecasts an average annual growth in demand of $1.2 \%$ for this fuel until 2040, which is two tenths lower than the forecast of the previous year [3]. Additionally, 
NG will reach second position within the most demanded energy sources in 2025 , surpassing coal and ranking just behind oil [1].

NG is the most environmentally friendly of the fossil fuels owing to the high hydrogencarbon ratio in its composition [4]. Moreover, it contains barely any trace of sulphur and NOx emissions in internal combustion engines are drastically reduced if the reaction is performed with lean mixtures. Thus, for these reasons, and considering the strategy of the International Maritime Organization (IMO) to cut greenhouse gases (GHG) by $50 \%$ in 2050 compared to 2008 [5], the use of NG in the maritime sector as an alternative to marine gas oil (MGO) or heavy fuel oil (HFO) could be of significant benefit until zero-emission fuel technologies are developed and implemented.

Fig. 1 illustrates the NG value chain, which can be divided into three main sectors: upstream (production and processing), midstream (transportation) and downstream (distribution and marketing). Raw gas, whether extracted from conventional or unconventional resources by means of different techniques, requires processing in order to meet the specifications of transport and distribution companies [6]. The treated gas can then be transported via a pipeline or in liquid state. Pipeline transportation is a cost-effective option for short distances (2200 miles onshore and 700 miles offshore) [4]. However, the liquefaction of gas (liquid state volume being 600 times less that of the gaseous state [7]) allows the compact storage of liquefied natural gas (LNG), and therefore long-distance maritime transport via LNG vessels to remote markets [8]. Before distribution to end users, the LNG needs to be regasified at import terminals.

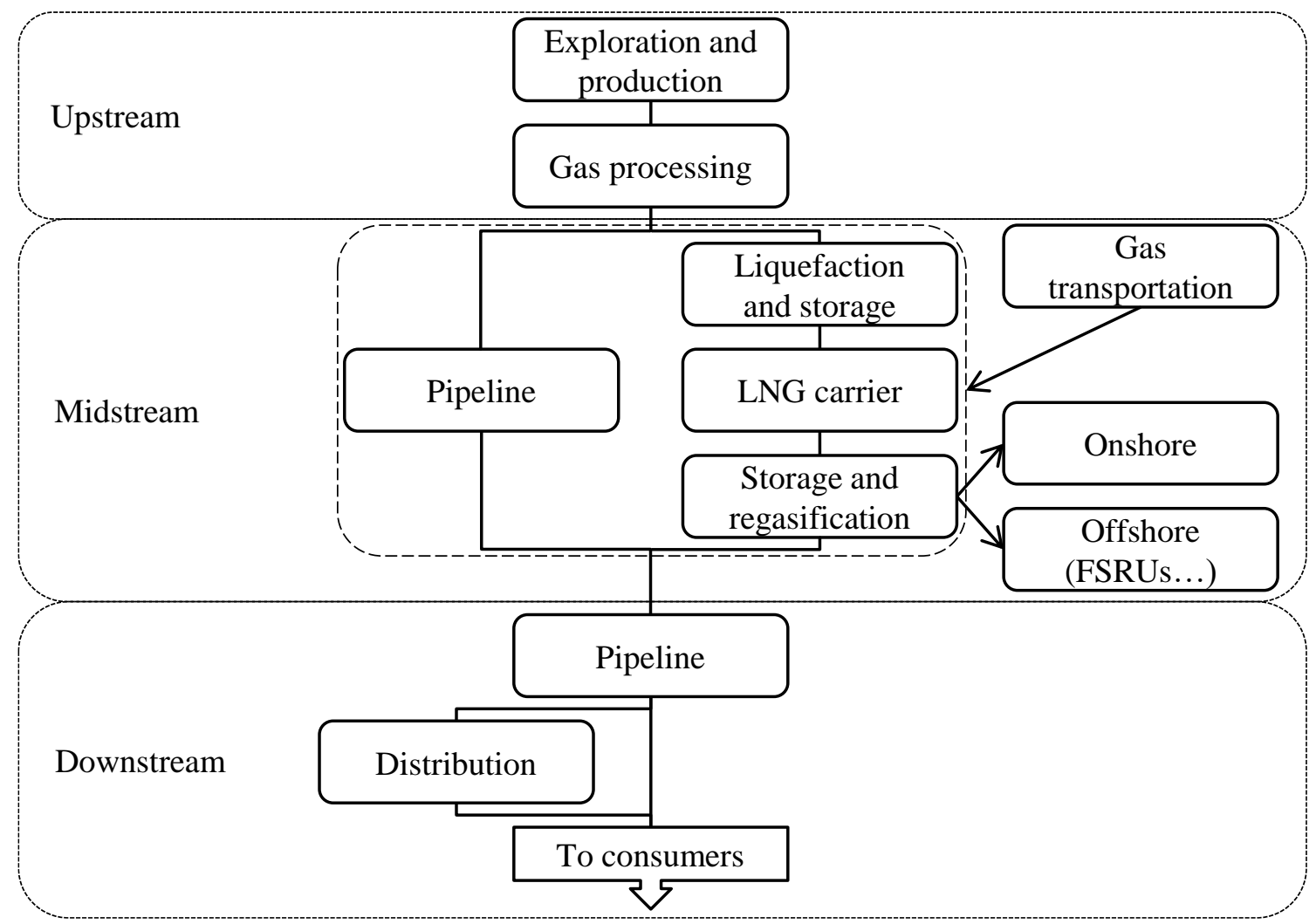

Fig. 1 Natural gas value chain

LNG regasification involves two basic processes in order to obtain suitable conditions in the gas pipeline distribution: pressure build-up and temperature increase. The process can be carried out in both onshore and offshore terminals. Onshore terminals have their own tanks or vessels for LNG storage termed Floating Storage Units (FSUs), whilst offshore terminals can be classified as Floating Storage and Regasification Units (FSRUs), Shuttle Regasification 
Vessels (SRVs) and Gravity Based Structures (GBSs). The main difference between an FSRU and SRV lies in the itinerant nature of the latter: while an FSRU is based at a specific location where it stores and regasifies the LNG transported by other vessels (transfer ship to ship, STS), the SRV transports the LNG and regasifies it by sending it through a submersible buoy (Submerged Turret Loading, STL) to a gas pipeline [4]. At present, the term FSRU generally identifies both, since SRVs are used as FSRUs.

In certain projects there are circumstances that favour the installation of FSRUs in onshore terminals. These factors may be politically motivated, or related to location, planning, public safety or environmental constraints [9]. Table 1 lists the main advantages and limitations of the installation of FSRUs.

Table 1 Some advantages and drawbacks of FSRUs [9-12]

\begin{tabular}{|c|c|}
\hline Advantages & Drawbacks \\
\hline $\begin{array}{l}\text { Low capital costs (CAPEX) due to compact } \\
\text { design. }\end{array}$ & $\begin{array}{l}\text { High operational costs (OPEX) if a charter } \\
\text { contract is established. }\end{array}$ \\
\hline $\begin{array}{l}\text { Versatility, if it has a suitable propulsion } \\
\text { system can operate as an LNG ship. }\end{array}$ & Reduced storage and regasification capacity. \\
\hline $\begin{array}{c}\text { Reduced time of construction and gas delivery } \\
\text { planning time. }\end{array}$ & $\begin{array}{l}\text { Difficulty in increasing the regasification or } \\
\text { storage capacity. }\end{array}$ \\
\hline $\begin{array}{l}\text { Flexibility, can operate in different locations } \\
\text { as needed. }\end{array}$ & $\begin{array}{c}\text { Susceptible to weather conditions, especially } \\
\text { in the open sea. }\end{array}$ \\
\hline $\begin{array}{c}\text { It reduces the "not in my back yard" (NIMBY) } \\
\text { movement. }\end{array}$ & $\begin{array}{c}\text { Reduced generation of employment in the } \\
\text { locality, both in the construction and operation } \\
\text { phases. }\end{array}$ \\
\hline
\end{tabular}

Despite the high number of scientific publications that address onshore regasification [13-17], which focus on the use of LNG cold energy, literature dealing on offshore regasification systems, specifically in FSRUs, is scarce. Hence the aim of this review is to study the regasification systems installed in FSRUs and the potential offered by the exploitation of cold energy from LNG in this vessel type.

The paper is set out as follows: Section 2 briefly provides the background and development of the FSRU fleet; Section 3 describes the current regasification system technology installed in FSRUs; Section 4 goes on to study the potential of the LNG cold energy and exergy recovery in FSRUs and the different power cycles proposed by several authors for its exploitation. To conclude, Section 5 summarizes the findings of the assessment.

\section{Historical background of the FSRUs}

The offshore regasification business began in 2001 with the development of the innovate Energy Bridge Regasification Vessel (EBRV) concept and its implementation on the Gulf Gateway Deepwater Port project [18]. The EBRV entailed the construction of an LNG vessel with the ability to regasify under varying environmental conditions and export the gas -whether offshore or docked- to a NG distribution network. Since the delivery of the first regasification vessel -the Excelsior- in 2005 to date, the development of the fleet can be split into two periods, clearly differentiated by the speed of construction and the propulsion technology adopted: 20052013 and 2014-present. Fig. 2 displays the evolution of the FSRU fleet up to 2020. 


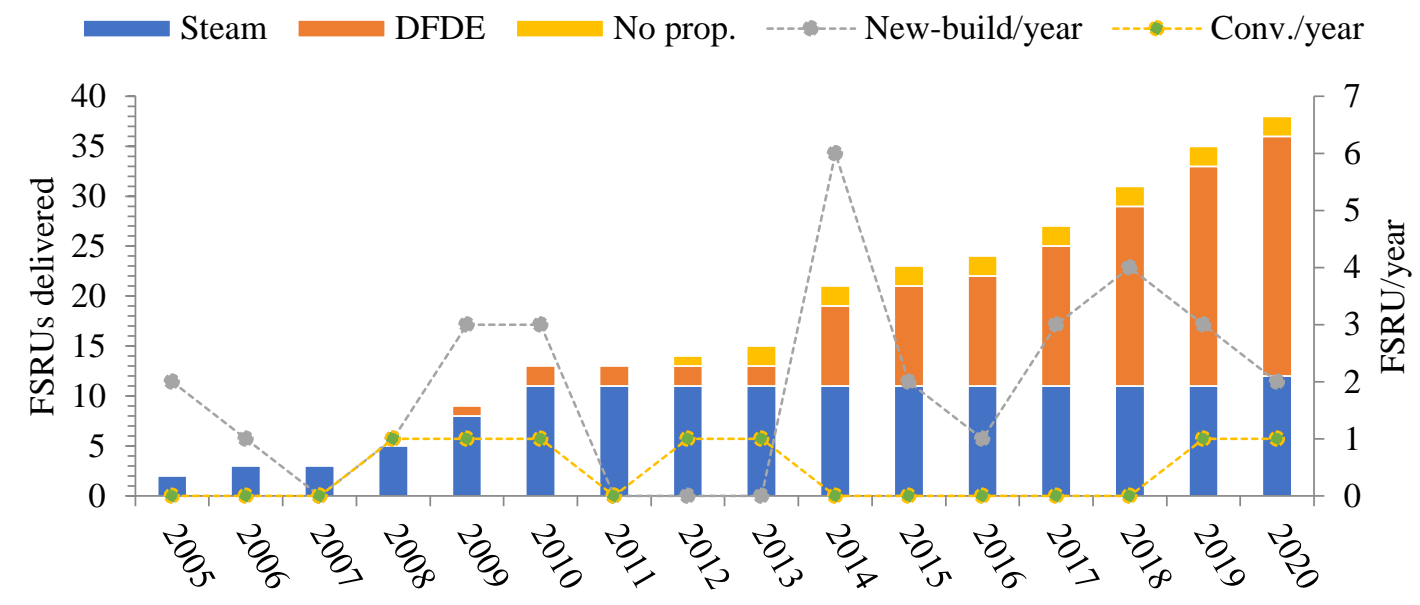

Fig. 2 Evolution of FSRU fleet

The 2005-2013 period is marked by the construction of the first FSRUs and the establishment of the sector's leading companies. Excelerate Energy and Golar LNG could initially be considered the pioneering companies in the development of offshore regasification [10]; the first in new builds and the latter in the conversion of existing LNG vessels. However, around the same time that Excelerate's EBRV came to being, Höegh LNG developed its own concept of regasification vessel: the LNG Shuttle and Regasification Vessel System (SRV) [19]. The growth of the fleet is rather inconsistent throughout the first period, with an average of 1.6 FSRUs per year. Moreover, there is a trend towards the building of FSRUs and conversions of LNG ships with steam propulsion systems. However, the building of the Neptune (2009) marked an important advance in propulsion technology, along with the entry of Hamworthy -a company acquired by Wärtsilä in 2012- in the regasification system market [20]. The Neptune was the first regasification vessel to feature dual fuel engine technology with an alternating current electric propulsion system, termed dual fuel diesel electric propulsion (DFDE); a more efficient system than the traditional steam turbine based propulsion $[21,22]$. By the end of 2013 there were a total of 15 FSRUs with the following main characteristics:

- 11 FSRUs featuring a steam turbine propulsion system, 8 of which were new-build and 3 LNG vessel conversions.

- 2 FSRUs with DFDE propulsion.

- 2 FSRUs without a propulsion system.

During the period from 2014-present, new builds of FSRUs with DFDE propulsion have predominated, and the growth of the fleet is more stable, averaging around 3.3 FSRUs per year (2014-2020), thereby more than doubling the previous period. As in the first period, most FSRUs are owned by Excelerate Energy, Golar LNG and Höegh LNG, but new companies such as the BW Group, MOL, Gazprom and Pardus Energy are emerging. By the end of 2020, the fleet increased to 38 FSRUs.

The pace of construction of FSRUs of recent years is set to continue in 2021, and several LNG vessel conversions are to be carried out. During 2021, the FSRU Ertrugul Gazi from BOTAS, two FSRUs from Dynagas, and the Jawa Satu FSRU will become operational, along with several LNG vessel conversions (BW Tatiana, Etyfa Prometheas and KARMOL LNGT Powership Africa) [23,24]. The last of the mentioned conversions will be used to supply NG to the powership located in Nacala, Mozambique [25]. Table A.1 lists the main characteristics of the existing FSRUs and specifies in which terminals they are operating. 
Exploitation of liquefied natural gas cold energy in Floating Storage Regasification Units
Manuel Naveiro, Manuel Romero Gómez, Ignacio Arias Fernández, Javier Romero Gómez

\section{Description of the FSRU technology}

LNG comprises a mixture of light hydrocarbons with nitrogen that is liquefied in landbased liquefaction terminals or in Floating LNG vessels (FLNG) for subsequent storage in tanks at a temperature of approximately $-162{ }^{\circ} \mathrm{C}$ and at a pressure slightly above atmospheric $[4,8]$. The LNG is stored in a natural convection boiling state [26]. While the tank insulation is designed to limit heat transfer from the environment, a small amount of vapor is generated, known as boil off gas (BOG) [27]. Under equilibrium conditions, BOG is composed of the most volatile substances present in LNG, namely, nitrogen and methane [26,28]. To keep the vapor pressure of the tanks within an acceptable range during LNG transport and storage, the BOG must be removed.

The loading operation in FSRUs, typically via STS transfer, is performed by means of arms or hoses installed in the port or starboard manifold of the regasification vessel [10]. The exchange of LNG and BOG takes place in the manifold. That is, the LNG is distributed towards the tanks and the BOG is extracted by the high-duty compressor to avoid excessive pressures. Most FSRUs use membrane tanks manufactured by GTT (MARK III, NO96, ...), though the conversions of old LNG carriers have spherical tanks, known as Moss type tanks. The maximum vapor pressure in recent FSRU builds when operating in regasification mode has increased to 0.7 bar $(\mathrm{g})[26,29]$. This allows the operating pressure range to be increased, thereby reducing the amount of BOG consumed in exceptional situations of high pressure in the tanks.

Fig. 3 is a general diagram of the LNG regasification process in FSRUs. The LNG extracted from the tanks by low pressure pumps (LP pumps) is supplied to the recondenser or suction drum. The LNG then goes to regasification trains, wherein it increases pressure and temperature via high pressure pumps (HP pumps) and vaporizers to achieve the supercritical conditions required for pipeline transportation. Before export, the metering station accurately determines the quantity and quality of the NG. The main components are briefly described in the following paragraphs.

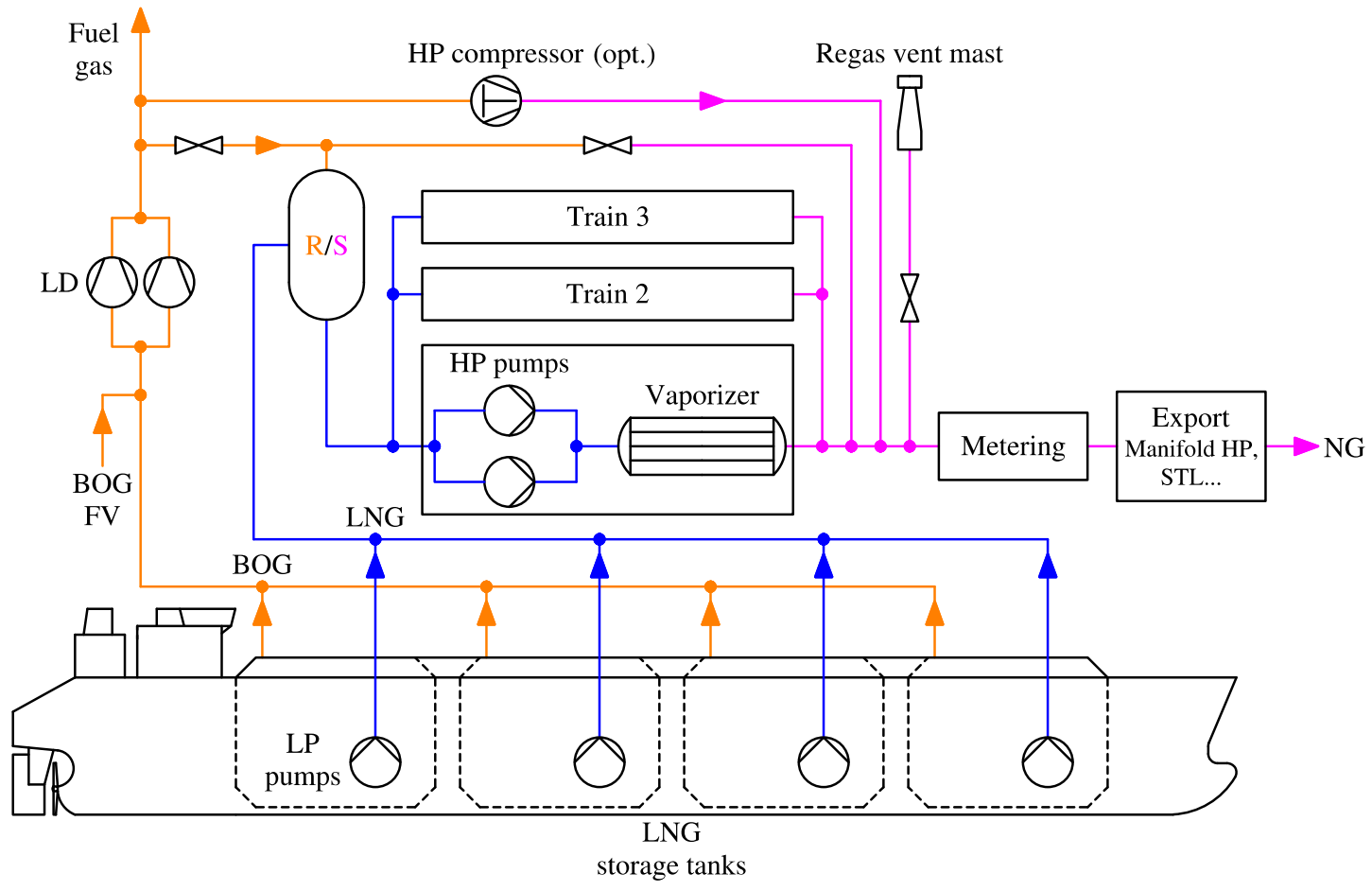

Fig. 3 Schematic of the regasification process in an FSRU 
LP pumps, also known as primary or feed pumps, are installed in the well of each tank and are of the vertical, submersible and single-stage centrifugal type [18]. In the event of breakdown, the primary pump can be removed from the well by previously inerting the column volume with nitrogen. Besides supplying the regasification system with LNG at a sufficient pressure, these pumps also perform the function of cargo pumps in the event of emergency.

Fig. 4 depicts the main differences between the suction drum and the recondenser. Currently, most new constructions are fitted with a recondenser, enabling the condensing of excess BOG. In early constructions and conversions, however, the recondenser is limited to a suction drum (Fig. 4a), whose function is to stabilize the fluctuations of the process and maintain a sufficient pressure to avoid high pressure pump cavitation [10]. Therefore, if consumption is not sufficient, the excess BOG in plants with DF engines is burned directly in the Gas Combustion Units (GCUs), while in steam plants a fictitious demand is generated in the boilers which directly tips the steam into the condenser (dumping). Moreover, the suction drum pressure is maintained with the regasified NG through a control valve (S), and there is also another in the LNG line to achieve an adequate liquid level.

a)

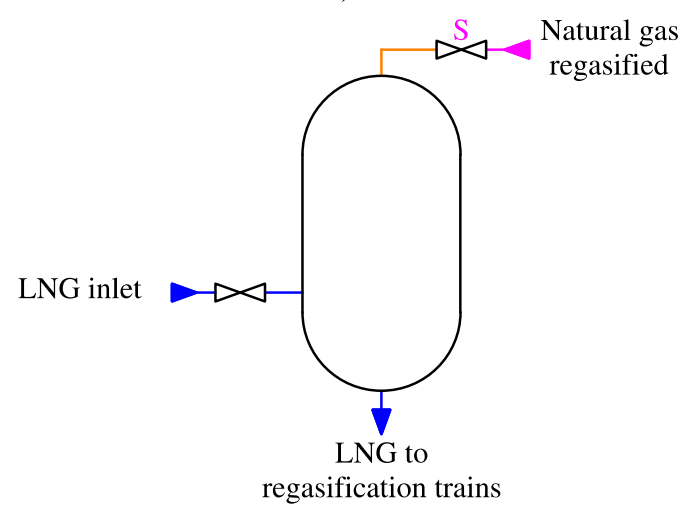

b)

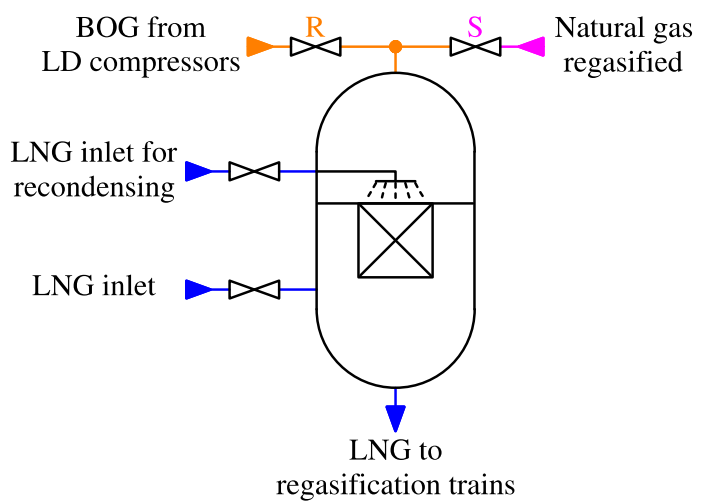

Fig. 4 Suction drum and recondenser: a) suction drum, b) recondenser

A second LNG line is installed in the upper part of the recondensers (Fig. 4b) that injects the liquid into the vapor zone, as well as a packed bed -or other components with a similar functionality- to improve the contact between both phases [30,31]. The regasified NG flow must be high enough to ensure an LNG flow that enables the BOG to condense and avoid the bubble point. This entails a more complex control system than that required for the previous situation, as well as the option of operating the recondenser as a suction drum when the BOG does not require condensing. Among the potential innovations in technology related to the BOG condensation process, noteworthy is Sulzer's static mixer (Fig. 5a) [32], installed on the Nusantara RegasSatu. Unlike conventional recondensers, the static mixer injects the BOG through a series of small holes perforated into a conduit through which the LNG flows internally, thereby guaranteeing sound contact between both phases and thus the effective condensation of the BOG in an inexpensive and compact unit. Wärtsilä [33] also improved the BOG recondensation system by proposing printed circuit heat exchangers (PCHE) at the outlet of the high-pressure pumps (Fig. 5b), which pre-cool the BOG before entering the recondenser. 
a)

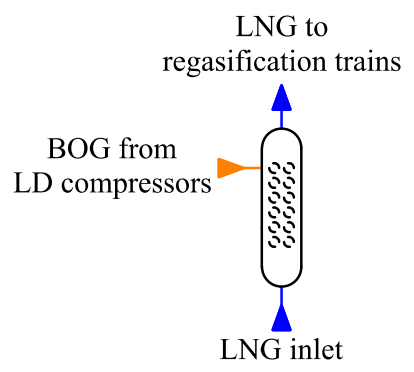

b)

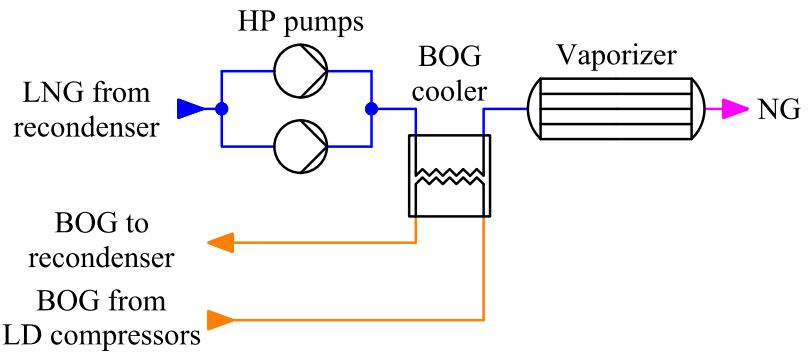

Fig. 5 Suction drum and recondenser: a) suction drum, b) recondenser

To condense the BOG, the low duty (LD) compressors must yield a higher pressure than that of the recondenser. This implies no relevant change in plants equipped with DF engines, since the pressure required in the recondenser is similar to the pressure of the engine gas valve units. These compressors are typically centrifugal and are usually of two types [34]: a two-stage compressor with BOG pre-cooling through the injection of LNG with a fuel gas pump (Fig. 6a) or a four-stage compressor (Fig. 6b). The latter can include the option of intermediate cooling between the higher pressure stages (2-3 and 3-4) [30,34]. The compressors are protected by a separator, located in the suction line, which returns the BOG condensables to one of the cargo tanks.

a)

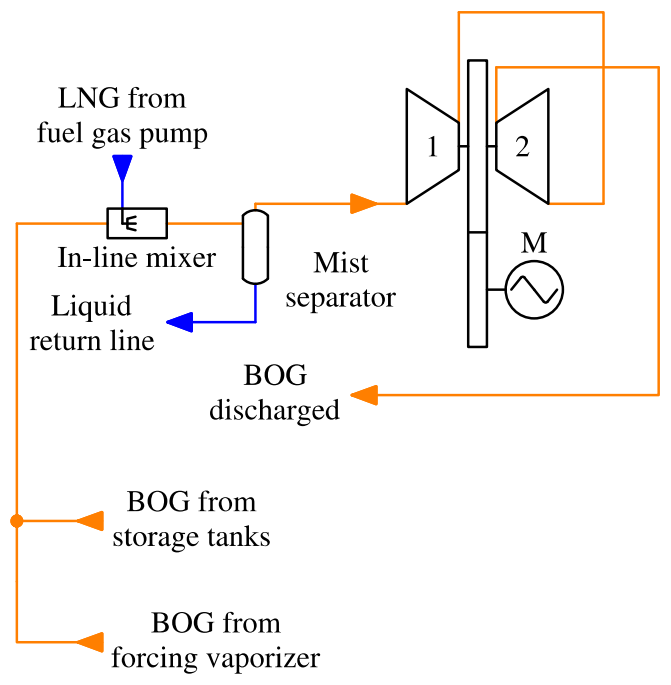

b)

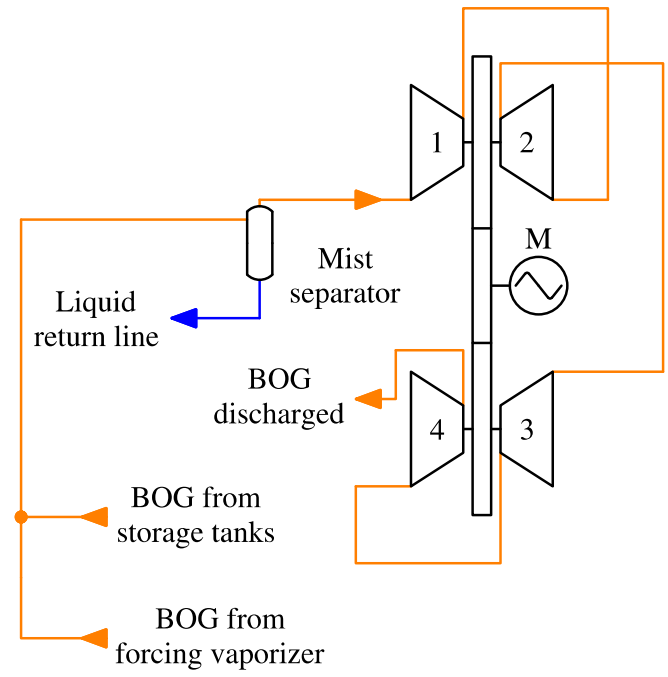

Fig. 6 Suction drum and recondenser: a) suction drum, b) recondenser

Some regasification systems, such as those developed for the Golar Freeze or the Explorer, are fitted with a high pressure reciprocating compressor that discharges the BOG from the LD compressors to the measurement unit for export $[35,36]$. Installation of these compressors increases flexibility when managing the BOG: for example, in low demand situations where it is not possible to condense all the BOG in the recondenser.

There are commonly three or four regasification trains and one of these, in certain cases, operates only as a backup or substitute. That is, the maximum regasification capacity may be below the total NG flows of all the trains. Currently, it is common for new builds to be equipped with three trains, each with a regasification capacity of 200-250 mmscfd [10,20], operating simultaneously in high-demand situations. Therefore, the baseload regasification capacity is of approximately $400-500 \mathrm{mmscfd}$, while the maximum reaches a value of $600-750 \mathrm{mmscfd}$. 
Some FSRUs, such as the Explorer or the Höegh Gannet, have a production capacity of up to 1000 mmscfd of NG [37,38]. Generally, each train is supplied with two high pressure pumps, known as secondary or booster pumps. These pumps are of the vertical, submersible and multistage centrifugal type $[18,39]$. Each pump is installed inside a suction pot, which is practically flooded. A small amount of BOG is generated due to the heat given off by the electric motor, which, if not discharged, would cause the level of liquid in the suction pot to drop to such a level that the control system would stop the pump to protect it [39]. This problem is of particular importance when the pumps are operating at low speed. Hence, the BOG is usually removed by connecting the upper part of the suction pot with the vapor line or with the recondenser. In both cases, the connection is via valves that guarantee an adequate liquid level required for pump operation. Regasified NG flow is controlled by a valve fitted in the liquid line at the vaporizer inlet. Section 3.1 includes the different methods or systems used in the LNG heating process.

The exportation of NG can be carried out via several methods, depending on the mooring system [10]. If the mooring is a jetty -whether on land or a jetty island- offloading can be carried out with hoses or arms through one of the high pressure manifolds, which are located forward of the loading manifolds. In offshore terminals, NG can be offloaded by means of a tower yoke or a submersible buoy (STL). FSRUs are usually fitted with one single export method, which can be high pressure manifolds (arms or hoses) or a tower yoke. However, SRVs have an STL system that can additionally come with high pressure manifolds.

\subsection{Regasification systems}

Regasification systems can be classified in terms of the heat source and the way in which heat exchange takes place between the source and the LNG. With regard to the heat source, the system can operate in an open, closed or combined loop. The open loop uses seawater while the closed loop indirectly uses the energy released in combustion processes, generally through steam produced in boilers. The combined loop, as its name suggests, involves both heat sources and is usually applied in situations where the seawater temperature is slightly lower than the design minimum [40]. Moreover, the heat exchange between the source and the LNG can be direct or indirect through an intermediate fluid circulating in a closed circuit. Table 2 lists the main regasification systems and their basic classification according to the operation loop and how heat exchange takes place.

Table 2 Basic classification of current regasification systems

\begin{tabular}{|c|c|c|c|}
\hline \multirow{2}{*}{\multicolumn{2}{|c|}{}} & \multicolumn{2}{c|}{ Heat exchange } \\
\cline { 3 - 4 } & \multirow{2}{*}{ Loop } & Direct & Indirect \\
\hline \multirow{3}{*}{ Loop } & Seawater & $\begin{array}{c}\text { Propane } \\
\text { Water-glycol }\end{array}$ \\
\cline { 2 - 4 } & \multirow{2}{*}{ Closed } & Steam & $\begin{array}{c}\text { Propane } \\
\text { Water-glycol } \\
\text { Water }\end{array}$ \\
\hline
\end{tabular}

Regasification systems installed in FSRUs are designed to run in at least one working loop. Complex regasification systems, which allow both open and closed loop operation, have a regasification method for each loop type. By way of example, the Excelerate Energy system [37] can run in open, closed or combined loop. In open-loop mode, the system uses seawater for regasification, while the closed-loop mode uses steam to heat the water that works as an intermediate fluid. On the other hand, propane open-loop regasification systems, such as that 
installed in the Golar Winter [39], can be fitted with steam heaters for the seawater, allowing closed-loop operation.

The choice of work loop must be approved by the administration and is normally reflected in an environmental impact report [41]. As a general rule, open loop is permitted as long as the seawater discharge temperature is not excessively cold. Countries such as the USA, however, have prohibited its use as a result of the damage caused to the marine ecosystem from the continuous discharge of seawater.

Regasification systems with closed-loop operation comply with the most stringent of regulations in place for the protection of the marine environment [10], but fuel consumption and thus, emissions of gases and particles are greater when compared with open-loop operation mode systems.

At present, some regasification ships use the energy dissipated in the refrigeration system of the ship's machinery for the regasification process [37,42]. This reduces the environmental impact caused by seawater usage and cuts fuel consumption in closed-loop systems.

Generally, if seawater usage is not prohibited, open-loop regasification systems are usually installed in most FSRUs, provided that there is an adequate ambient temperature on site throughout the year. The main regasification systems installed in FSRUs are described below.

\subsubsection{Direct regasification systems}

Direct heat exchange regasification systems were the first to be implemented on board FSRUs. Simplicity is what characterizes these systems, along with the installation of shell and tube heat exchangers without intermediate fluids in the heat transfer process. Fig. 7 shows the two types of direct exchange systems; the first designed to operate exclusively in closed loop, and the second for open-loop running with the option of fitting a steam heater that allows closed or combined-loop operation.

Fig. 7a corresponds to a steam regasification train developed by Moss Maritime, resembling that installed on the Golar Spirit [43]. The train comprises one or two high-pressure pumps, a vaporizer, two control valves -one for the flow and the other for the regasified NG temperature- and a static mixer. The mixer features three helical elements designed to guarantee the mixing of the two flows, removing differences in temperature and composition between both. The Golar Spirit [44] was fitted with a module that included three regasification trains with a redundancy of $50 \%$ of the maximum regasification capacity $(3 \times 50 \%)$. Additionally, each train has a high pressure pump and uses low pressure saturated steam $(<10 \mathrm{bar})$ in the vaporizer. The Golar Spirit has been the only FSRU to adopt such a regasification system.

The main advantage of steam regasification systems lies in the compact design of the heat exchangers. This is owing to the high temperature difference between the saturated steam and $\mathrm{NG}$, as well as to the advantages of steam condensation, which provides a high film coefficient and low mass flow due to the latent heat from the phase change. Moreover, the use of noncorrosive fluids means that conventional stainless steel can be used to build the heat exchangers; hence, inexpensive and smaller scale shell-and-tube exchangers. Therefore, the regasification trains are compact in size and low in weight, making them easier to situate on the FSRU deck.

From an energy and even economic standpoint, however, should operational costs be included, these regasification systems are totally inefficient owing to the fact they require considerable fuel input to produce the regasification process steam. What is more, such a system requires the use of fuel at a level equivalent to approximately $2.5 \%$ of the amount of regasified $\mathrm{NG}$ [33]. Further to this is also the detrimental impact of the $\mathrm{CO}_{2}$ produced by $\mathrm{NG}$ combustion in the boilers. 


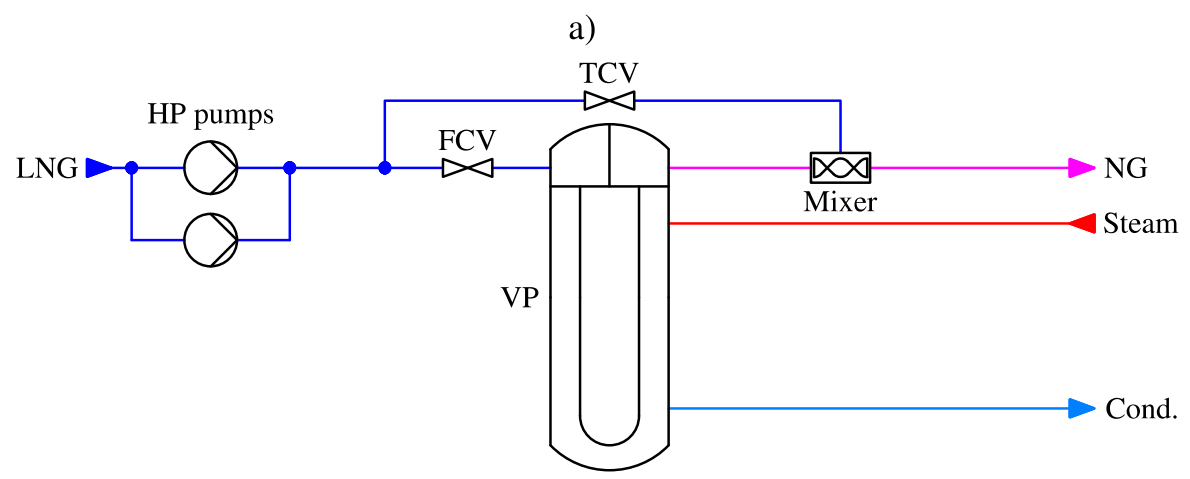

b)

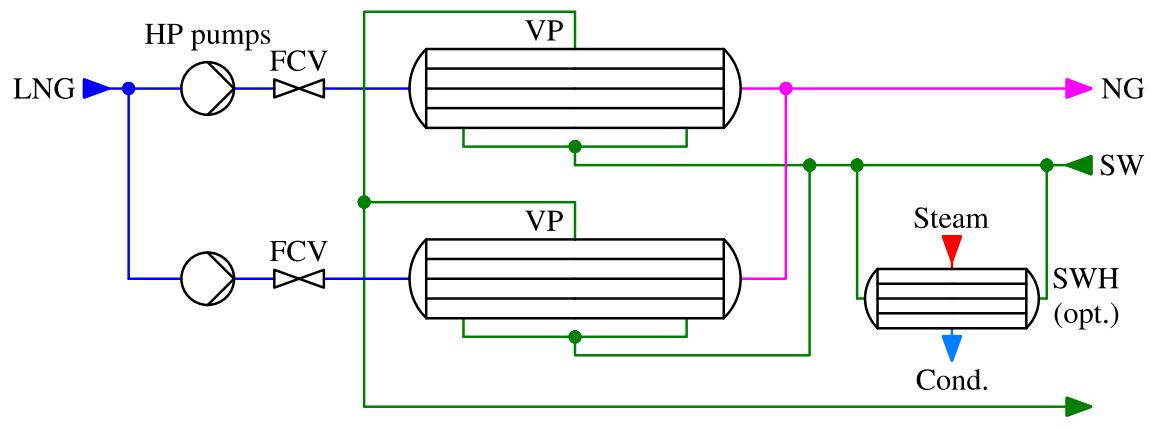

Fig. 7 Direct regasification systems: a) steam regasification train, b) seawater regasification

In countries where the use of sea water is permitted, and its temperature is adequate, openloop systems are more efficient than the others since they only require power for the pumps. Fig. 7b illustrates a module comprising two seawater regasification trains with an optional heater. Typically, up to six regasification trains are installed. The first FSRUs -built by Excelerate Energy- yielded a redundancy of $20 \%$ [18], although in recent constructions the approach is to remove this redundancy and increase regasification capacity [10].

The vaporizers are shell and tube heat exchangers, specifically of the NJN type with an expansion joint [45], but their size and cost is far more than those installed in steam regasification trains. The exchangers are of such a large size because of the minimum temperature difference $\left(5-7^{\circ} \mathrm{C}\right)$ and because the seawater remains in a liquid state during the LNG vaporization process. Also, a very high flow is required for compliance with the permitted maximum seawater discharge temperature differential (around $5{ }^{\circ} \mathrm{C}$ ), thus affecting equipment size and pump consumption. The costliness of the vaporizers is not only owing to the heat exchange surface, but also to the construction material: seawater is a corrosive fluid thereby requiring the use of titanium or special stainless steel alloys with a high content of nickel and molybdenum (254 SMO, AL-6XN, ...) [29].

Despite the high investment costs involved with seawater regasification trains, fuel savings are considerable and so operating costs are drastically reduced when compared with closed-loop systems [10].

Moreover, seawater is a "dirty" fluid that requires efficient filtering for the sound functioning of the vaporizers, which can only be cleaned chemically. Account also has to be taken of the risk of freezing in the vaporizer due to the use of seawater in direct exchange with LNG [33]. The latter has been a determining factor for the implementing of regasification systems with intermediate fluids. 


\subsubsection{Propane regasification systems}

Propane regasification systems have been installed in several FSRUs. It was not until recently, in fact, that these, along with those of direct exchange with seawater, became the most common regasification systems. The great advantage of this system is that there is no risk of freezing in the vaporizer: the propane freezing point $\left(-188{ }^{\circ} \mathrm{C}\right)$ is lower than the LNG temperature [4]. Fig. 8 depicts the most relevant propane regasification trains installed in FSRUs.

a)



b)

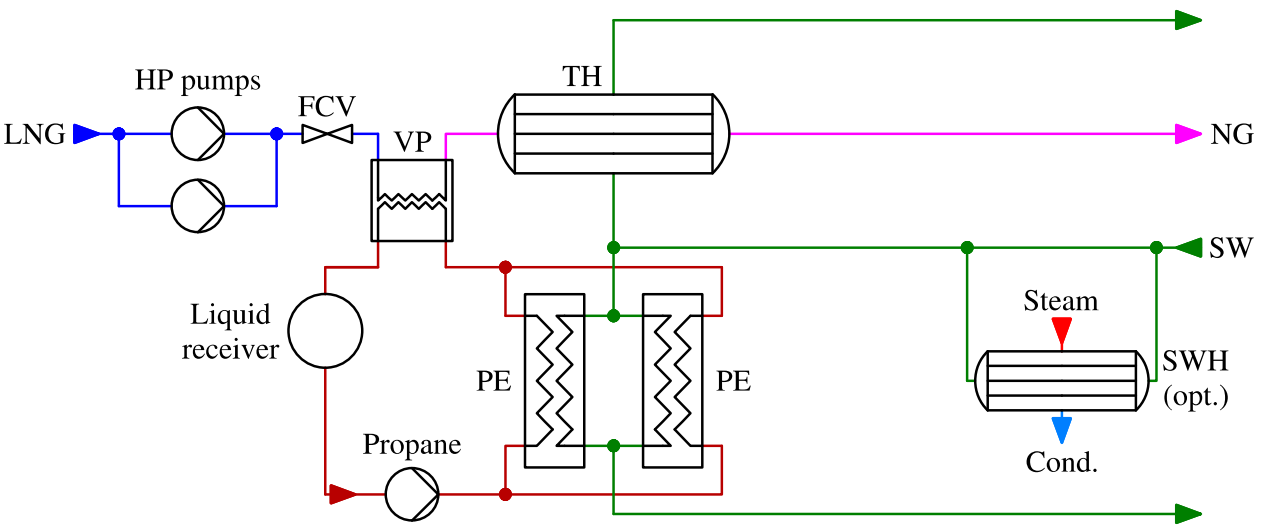

c)

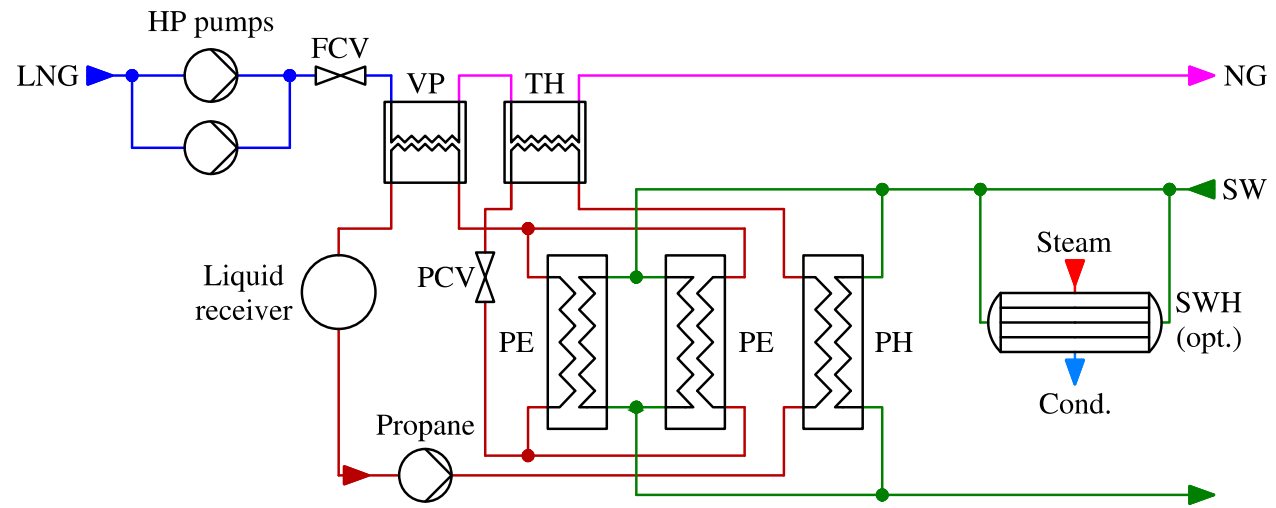

Fig. 8 Propane regasification systems: a) Intermediate Fluid Vaporizer (IFV), b) former propane regasification train, c) current propane regasification train

During the regasification process in these systems, propane is vaporized by seawater and is then condensed in the LNG vaporizer, thus exploiting the latent heat in both processes, and consequently reducing the mass flow of propane. Furthermore, the heat exchangers are compact due to the high global heat transfer coefficient. 
The Intermediate Fluid Vaporizer (IFV) in Fig. 8a has been widely installed in onshore regasification terminals, although there is only one example in FSRUs: The Toscana FSRU [46]. The IFV is divided into three sections or exchangers: LNG vaporizer, propane vaporizer and NG trim heater with seawater. The LNG vaporizer condenses the propane that drops over the vaporizer of the latter. Meanwhile, the seawater flows first through the NG trim heater and then through the propane vaporizer. The main feature of this system, besides the integration of three exchangers into one, is that the propane flows through natural convection inside the shell [47]. The pipes in contact with the seawater are of titanium, which reduces maintenance costs, but can be rather bulky in size, especially the casing that houses the propane condensation and boiling process.

In view of the need to design compact regasification systems, Wärtsilä installed three regasification trains, as per Fig. 8b [33]. The regasification system installed in the Golar Winter, unlike the Golar Freeze, includes steam seawater heaters in order to be able to operate in a closed loop [39]. The train, besides comprising the high-pressure pumps and flow control valve, is fitted with a PCHE type vaporizer, a trim heater, a centrifugal pump to drive the propane through the closed circuit, a liquid container, and two propane vaporizers. The use of "clean" fluids with a lower freezing point than the LNG temperature allows and guarantees the smooth running of the PCHEs. The PCHEs, made of stainless steel, tolerate wide temperature ranges (from cryogenic to $900{ }^{\circ} \mathrm{C}$ ) and high pressures (600 bar or more). Additionally, they are 4-6 times smaller than conventional shell-and-tube exchangers for the same duty, and so can be considered a type of compact heat exchanger, ideal for usage in a reduced space, as in the case of FSRUs [33]. Propane vaporizers are titanium semi-welded plate heat exchangers, containing flammable fluid under pressure that flows within the welded sides. This exchanger type can be disassembled to clean the sides that are in contact with sea water, this being a significant maintenance advantage over welded shell-and-tube heat exchangers. The other strong point is its more compact design owing to a high heat transfer coefficient.

Wärtsilä perfected the propane regasification system by replacing the seawater NG trim heater (titanium shell-and-tube welded exchanger) with a second PCHE running on propane in a sub-cooling liquid state (Fig. 8c) [33,39]. Thus, all heat exchangers in contact with seawater are of semi-welded plates that can be disassembled and cleaned to effectively remove marine growth. Liquid propane, which is at a pressure higher than the vaporizers, increases its temperature in the preheater before entering the PCHE that operates as a trim heater. The propane expands at the outlet through a pressure control valve and flows towards the two vaporizers. As they are plate heat exchangers, the pinch point is lower, thereby allowing the natural gas end temperature to be effectively controlled in the trim heater.

\subsubsection{Water-glycol regasification systems}

Regasification systems that use a water-glycol mixture as an intermediate fluid were originally proposed as an alternative to direct exchange steam systems. In recent years, however, water-glycol systems capable of operating in open-loop have been installed, are currently cornering the market. Fig. 9 illustrates the different water-glycol regasification trains for FSRUs.

The use of a water-glycol mixture as an intermediate fluid reduces the freezing temperature (around $-30{ }^{\circ} \mathrm{C}$ ) compared to pure water, which depends on the glycol content in the composition. However, the mixture does not undergo phase change processes: Hence, as it is devoid of latent heat, a high mass flow is required, which must be taken into consideration when dimensioning the installation, especially pump consumption. Besides its high availability and low cost, the main advantage of the water-glycol mixture is that it is a non-flammable fluid. 
a)

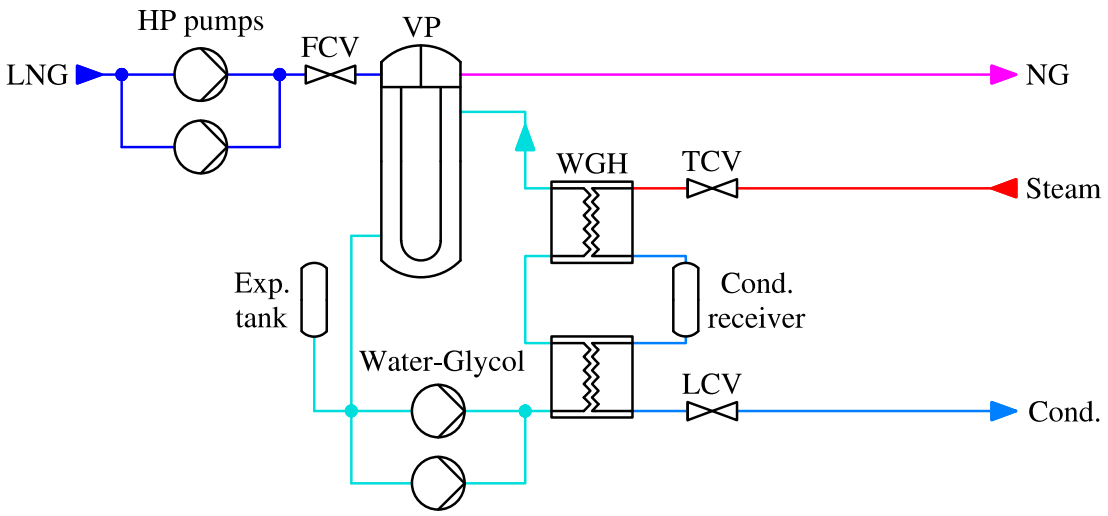

b)

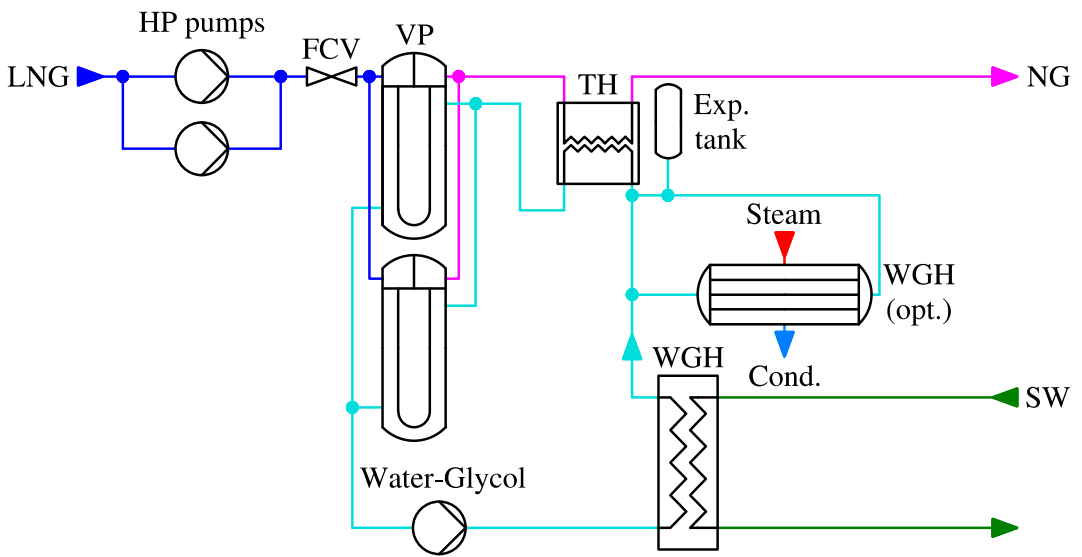

c)

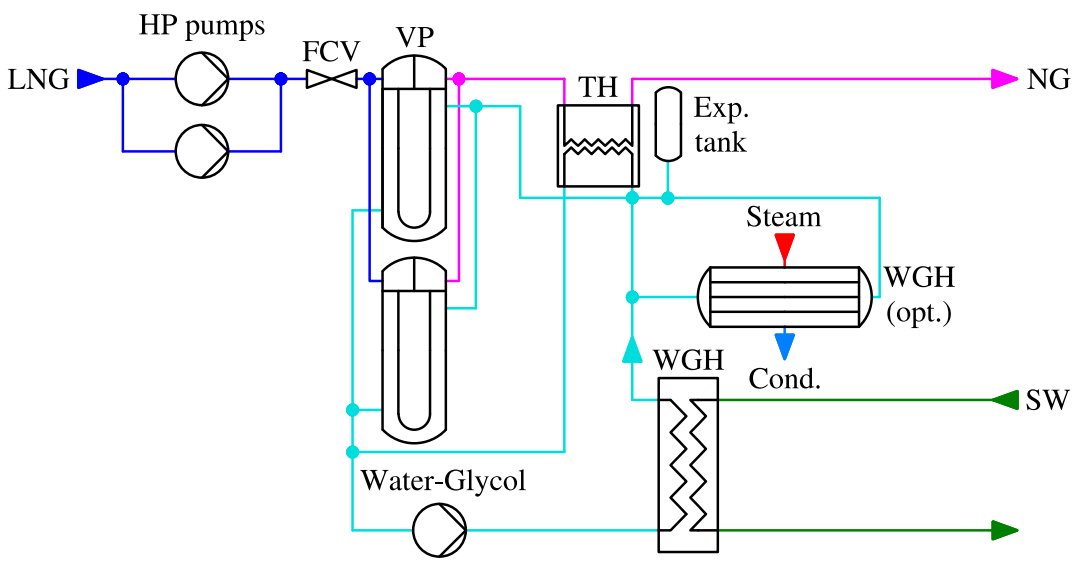

Fig. 9 Water-glycol regasification systems: a) closed-loop train, b) series regasification train, c) parallel regasification train

Fig. 9a depicts the first water-glycol regasification train installed on regasification vessels as an alternative to steam direct exchange systems $[39,48]$. Specifically, three trains were fitted on the Neptune and her sister ship, the Cape Anne. The train comprises two high pressure pumps, a NG flow control valve, an LNG vaporizer, an expansion tank, two centrifugal pumps (one in standby) for the glycol water mixture, a water-glycol heater divided into two sections, a condensate receiver with its corresponding level control valve, and a valve to control the flow of steam in order to achieve an adequate temperature of the regasified NG. The vaporizer is a stainless steel shell and tube exchanger in which the mixture enters at $90{ }^{\circ} \mathrm{C}$ and exits at $30^{\circ} \mathrm{C}$. The splitting of the water-glycol heater is to avoid steam condensed fluctuations internally that 
could cause thermal fatigue. Therefore, the saturated steam at 23-25 bar condenses in the first PCHE, while the condensed steam is cooled in the second. Besides reducing the risk of freezing, this system shares the main strengths and weaknesses of steam regasification trains in direct exchange. Train design is compact and economical, but operational costs are high due to fuel consumption in the boilers. The only regasification vessels to install such a system are the two above-named.

Figs. $9 \mathrm{~b}$ and 9c illustrate two possible open-loop regasification train configurations with water-glycol mixture $[45,49,50]$. In the first option, the vaporizers and the trim heater are in series, while the second is a parallel layout. These trains can be fitted with steam heaters for closed-loop operation. As it is a water-glycol mixture, there are potential freezing issues in the vaporizers and so shell and tube exchangers are usually installed instead of PCHEs. A PCHE is usually fitted downstream to reduce the size of these heat exchangers and of the regasification train, The NG temperature at the PCHE inlet (around $-20^{\circ} \mathrm{C}$ ) must be higher than the waterglycol mixture freezing temperature. All heat exchangers -with the exception of the waterglycol heater with seawater- are made of stainless steel. The seawater heater is a gasket plate heat exchanger built of titanium to prevent corrosion. These trains offer a simple and safe regasification system that does not involve phase change processes, the use of flammable fluids under pressure, nor does it give rise to corrosion problems. Additionally, most of the heat exchangers are built with conventional stainless steels and so are inexpensive. On the down side, the intermediate fluid pump consumption is greater in contrast to propane regasification trains, due to the high water-glycol mass flow required for the LNG regasification process.

\section{LNG cold energy}

The term cold energy -applied to LNG regasification systems- can be defined as the energy transferred in the form of heat from LNG to the hot fluid. This energy is acquired in the NG liquefaction process for storage and transportation in a liquid state.

Analogously, in exergy terms, LNG cold exergy can be defined in terms of the physical exergy components. Physical exergy is the maximum work that can be developed when evolving from any thermodynamic state to the reference state temperature and pressure. Therefore, the flow specific physical exergy $\left(e^{\mathrm{ph}}\right)$ is determined as:

$$
e^{\mathrm{ph}}=h-h_{0}-T_{0}\left(s-s_{0}\right)
$$

Physical exergy can be decomposed into thermal exergy $\left(e^{\text {th }}\right)$ and mechanical exergy $\left(e^{\mathrm{p}}\right)$ :

$$
e^{\mathrm{ph}}=e^{\mathrm{th}}+e^{\mathrm{p}}
$$

However, the unambiguous calculation of the components is only possible for ideal gases and incompressible fluids [51]. For any fluid, thermal and mechanical exergy are usually determined as follows:

$$
\begin{aligned}
& e^{\text {th }}=e^{\mathrm{ph}}(T, p)-e^{\mathrm{ph}}\left(T_{0}, p\right) \\
& e^{\mathrm{p}}=e^{\mathrm{ph}}\left(T_{0}, p\right)-e^{\mathrm{ph}}\left(T_{0}, p_{0}\right)
\end{aligned}
$$

Therefore, if physical exergy is broken down into its components, cold exergy can be defined as the change in thermal exergy experienced by LNG in the vaporizer. That is, the maximum work that can be generated due to the temperature difference between the LNG and regasified NG. 


\subsection{Energy and exergy analysis}

The amount of cold energy and exergy released in the regasification process of an FSRU is determined below Fig.10a. The LNG composition and the conditions used for calculation are listed respectively in Tables 3 and 4. The NG flow represents the typical FSRU baseload regasification capacity. Thermodynamic properties are determined applying the GERG2008 equation of state in the Aspen HYSYS.

a)

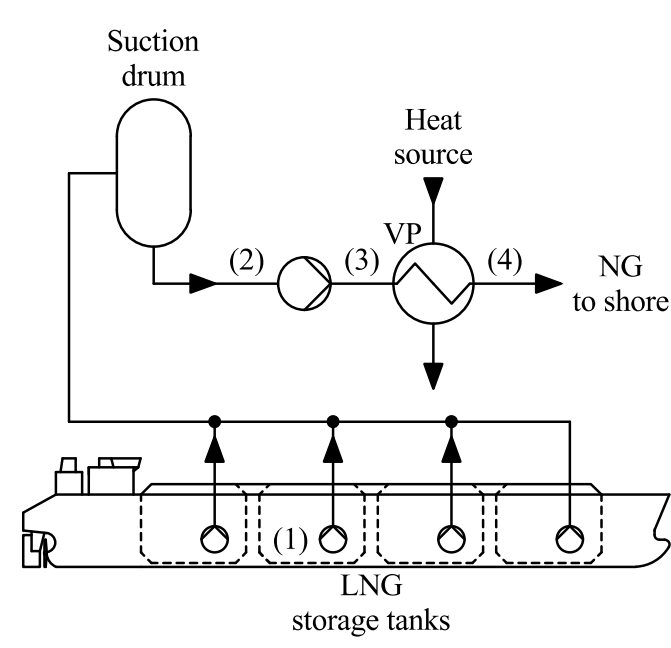

b)

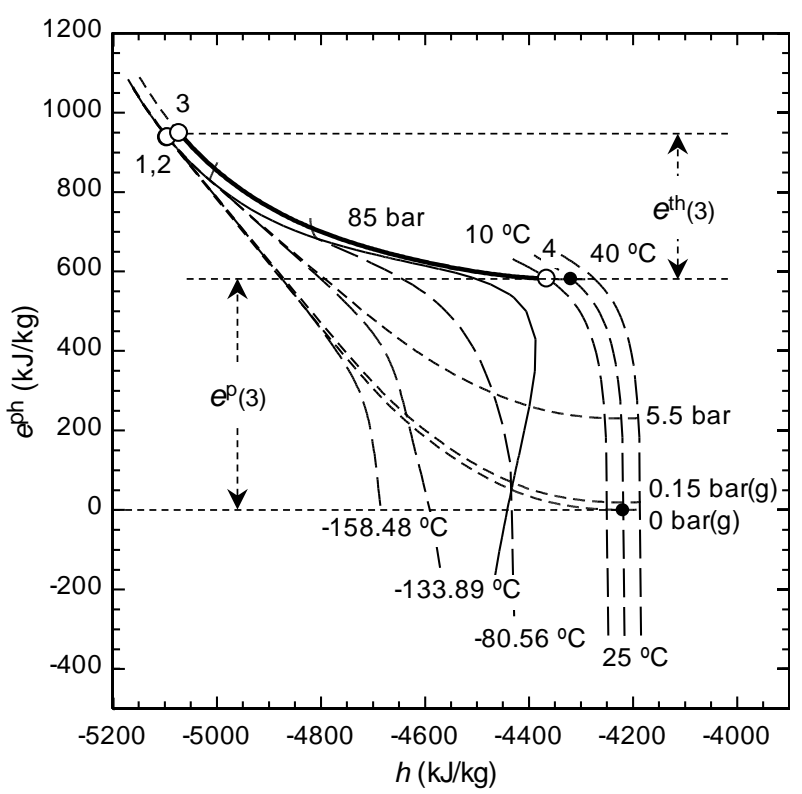

Fig. 10 Regasification process in a FSRU: a) simplified scheme, b) $e^{\mathrm{ph}}-h$ diagram

Table 3 Natural gas composition measured on board a FSRU

\begin{tabular}{|c|c|}
\hline Component & Mole fraction \\
\hline Methane $\left(\mathrm{CH}_{4}\right)$ & 0.89018 \\
\hline Nitrogen $\left(\mathrm{N}_{2}\right)$ & 0.00007 \\
\hline Carbon dioxide $\left(\mathrm{CO}_{2}\right)$ & 0.00000 \\
\hline Ethane $\left(\mathrm{C}_{2} \mathrm{H}_{6}\right)$ & 0.07974 \\
\hline Propane $\left(\mathrm{C}_{3} \mathrm{H}_{8}\right)$ & 0.02291 \\
\hline i-Butane $\left(\mathrm{i}-\mathrm{C}_{4} \mathrm{H}_{10}\right)$ & 0.00322 \\
\hline n-Butane $\left(\mathrm{n}-\mathrm{C}_{4} \mathrm{H}_{10}\right)$ & 0.00371 \\
\hline i-Pentane $\left(\mathrm{i}-\mathrm{C}_{5} \mathrm{H}_{12}\right)$ & 0.00014 \\
\hline n-Pentane $\left(\mathrm{n}-\mathrm{C}_{5} \mathrm{H}_{12}\right)$ & 0.00002 \\
\hline n-Hexane $\left(\mathrm{n}-\mathrm{C}_{6} \mathrm{H}_{14}\right)$ & 0.00001 \\
\hline
\end{tabular}

Fig. $10 \mathrm{~b}$ depicts the different states of the regasification process in an $e^{\mathrm{ph}}-h$ diagram. This type of diagram allows the process to be simultaneously displayed from both an energy and exergy perspective. Table 5 details the thermodynamic properties in each of the states, including those mentioned above. LNG stored in saturated liquid conditions at tank pressure (state 1) is driven by the feed pump towards the suction drum (state 2). Next, the booster pump increases the LNG pressure up to the value required for the distribution of NG through the gas pipeline 
(state 3). Increasing the LNG pressure subsequently increases the fluid energy and exergy content. However, part of the thermal exergy is transformed into mechanical exergy. Thus, the thermal component of the LNG in the tank represents $97.99 \%$ of the physical exergy, while at the booster pump outlet the value drops to $38.76 \%$. Finally, the LNG enters the vaporizer where the NG reaches a temperature (state 4) approaching that of the reference state. It is because of this that the enthalpy in state 4 increases, but the physical exergy decreases $38.64 \%$ with respect to the previous state.

Table 4 LNG regasification process data

\begin{tabular}{|c|c|}
\hline Parameter & Value \\
\hline LNG storage pressure & $1.16325 \mathrm{bar}$ \\
\hline Suction drum pressure & $5.50 \mathrm{bar}$ \\
\hline Regasified natural gas pressure & $85.00 \mathrm{bar}$ \\
\hline Regasified natural gas temperature & $10.00^{\circ} \mathrm{C}$ \\
\hline Regasified natural gas flow & $500 \mathrm{mmscfd}$ \\
\hline Pumps isentropic efficiency & $80.00 \%$ \\
\hline
\end{tabular}

Table 5 Thermodynamic data of the regasification process

\begin{tabular}{|c|c|c|c|c|c|c|c|c|}
\hline State & $\begin{array}{c}\boldsymbol{T} \\
\left({ }^{\mathbf{o}} \mathbf{C}\right)\end{array}$ & $\begin{array}{c}\boldsymbol{p} \\
(\mathbf{b a r})\end{array}$ & $\begin{array}{c}\boldsymbol{h} \\
(\mathbf{k J} / \mathbf{k g})\end{array}$ & $\begin{array}{c}\boldsymbol{s} \\
(\mathbf{k J} / \mathbf{k g}- \\
\mathbf{K})\end{array}$ & $\begin{array}{c}\boldsymbol{\rho} \\
\left(\mathbf{k g} / \mathbf{m}^{\mathbf{3}}\right)\end{array}$ & $\begin{array}{c}\boldsymbol{e}^{\mathbf{p h}} \\
(\mathbf{k J} / \mathbf{k g})\end{array}$ & $\begin{array}{c}\boldsymbol{e}^{\mathbf{p}} \\
(\boldsymbol{\%})\end{array}$ & $\begin{array}{c}\boldsymbol{e}^{\mathbf{t h}} \\
(\%)\end{array}$ \\
\hline 1 & -158.48 & 1.16325 & -5094.41 & -11.103 & 457.28 & 936.72 & 2.01 & 97.99 \\
\hline 2 & -158.31 & 5.50 & -5093.23 & -11.101 & 457.40 & 937.29 & 24.56 & 75.44 \\
\hline 3 & -155.03 & 85.00 & -5071.50 & -11.063 & 459.52 & 947.79 & 61.24 & 38.76 \\
\hline 4 & 10.00 & 85.00 & -4364.23 & -7.463 & 84.77 & 581.60 & 99.79 & 0.21 \\
\hline
\end{tabular}

The cold energy $\left(\dot{H}_{\mathrm{LNG}}\right)$ and cold exergy $\left(\dot{E}_{\mathrm{LNG}}\right)$ are calculated by applying the steadystate energy and exergy balances to the NG flowing through the vaporizer:

$$
\begin{aligned}
& \dot{H}_{\mathrm{LNG}}=-\dot{m}_{\mathrm{NG}}\left(h_{3}-h_{4}\right) \\
& \dot{E}_{\mathrm{LNG}}^{\mathrm{th}}=\dot{m}_{\mathrm{NG}}\left(e_{3}^{\mathrm{th}}-e_{4}^{\mathrm{th}}\right)
\end{aligned}
$$

The results are listed in Table 6.

Table 6 Thermodynamic data of the regasification process

\begin{tabular}{|c|c|c|}
\hline \multirow{2}{*}{ Parameter } & \multicolumn{2}{|c|}{ Regasified natural gas flow } \\
\cline { 2 - 3 } & $\begin{array}{c}\text { Specific } \\
(\mathbf{k J} / \mathbf{k g})\end{array}$ & $\begin{array}{c}\mathbf{5 0 0} \mathbf{~ m m s c f d} \\
(\mathbf{k W})\end{array}$ \\
\hline LNG cold energy & 707.27 & 88811.36 \\
\hline LNG cold exergy & 366.19 & 45981.70 \\
\hline
\end{tabular}

Current regasification systems dispose of most of the cold energy or exergy, making barely any effective use of it. Thus, the cold energy becomes one more residual energy source of the FSRU. 
With this in mind, it is of interest to compare the LNG cold energy with the main source of residual energy in conventional ships, that is, exhaust gases, from an energy and exergy standpoint. Four-stroke dual fuel engines are usually installed in FSRUs for electricity generation. The exhaust gas temperature, running on $\mathrm{NG}$, exceeds $400{ }^{\circ} \mathrm{C}$ at the turbocharger outlet [52]. Considering exhaust gases behave like ideal gas, with a specific heat at a constant pressure of $1.06 \mathrm{~kJ} / \mathrm{kg}^{\circ} \mathrm{C}$, and a minimum utilization temperature of $100{ }^{\circ} \mathrm{C}$, the specific energy and exergy available for a temperature of $430^{\circ} \mathrm{C}$ is of 342.88 and $146.60 \mathrm{~kJ} / \mathrm{kg}$, respectively.

In specific units, LNG cold energy of LNG is 2.06 times that of the exhaust gases, while in exergy terms, this value increases to 2.50 . Moreover, it is to be taken into account that the regasified NG flow under base load conditions is greater than that of the engine exhaust gases. It is for these reasons that the most significant source of residual energy in an FSRU where efforts must be focused is the utilization of LNG cold energy.

Current regasification systems usually only take advantage of a small amount of LNG cold energy to condense the BOG coming from the tanks. The utilization or exploitation of the LNG cold energy, however, is usually understood to be its use in systems external to the regasification process and, in particular, its application in power thermodynamic cycles [16].

\subsection{Power cycles for cold energy recovery}

In the particular case of offshore regasification, the use of cold energy for power generation would reduce fuel consumption and emissions from internal combustion engines or boilers in plants with turbogenerators. What is more, for a typical regasification flow of 500 mmscfd, the available cold exergy is approximately four times that of the power demand of the FSRU (about 10-12 MW). Regasification systems that integrate power cycles can be classified into three types, depending on the level of cold energy exploitation:

- Regasification systems with low-level exploitation of cold energy. This type includes those systems that supply a percentage of the power demand required in the FSRU.

- Regasification systems with a medium-level exploitation of cold energy. Such systems are capable of totally supplying the FSRU power demand.

- Regasification systems with high-level exploitation of cold energy: The systems generate enough power to install energy storage systems or export it to land.

Under this classification, low and medium level systems have the advantage of a more compact and simple design compared with the high level. The latter, nevertheless, would be an interesting option in "LNG to power" projects, especially those where the FSRU power generation can be combined with that of an LNG powership, thus delivering a high-efficiency floating power plant with low emissions.

As yet there are no FSRUs that produce electricity by taking advantage of the LNG cold energy. However, MOL and DSME [53] recently developed the first regasification system with cold energy exploitation, which includes an Organic Rankine Cycle (ORC) that uses seawater as the hot source and LNG as the sink. It is also fitted with a trim heater that uses a water-glycol mixture as an intermediate fluid in the heat transfer between NG and seawater [54].

Scientific publications that address the use of cold energy in FSRUs are scarce. Tianbiao et al. [16], despite considering power generation as the main application of cold energy in FSRUs, point out the limited space on deck and the need to design compact equipment as key to its real application. As regards power cycles proposed in the existing publications, most are based on the ORC technology, specifically configurations of ORCs associated in series or in cascade as illustrated in Figs. 11 and 12, evaluating different working fluids, both pure fluids and zeotropic mixtures. 
Manuel Naveiro, Manuel Romero Gómez, Ignacio Arias Fernández, Javier Romero Gómez
Exploitation of liquefied natural gas cold energy in Floating Storage Regasification Units

a)

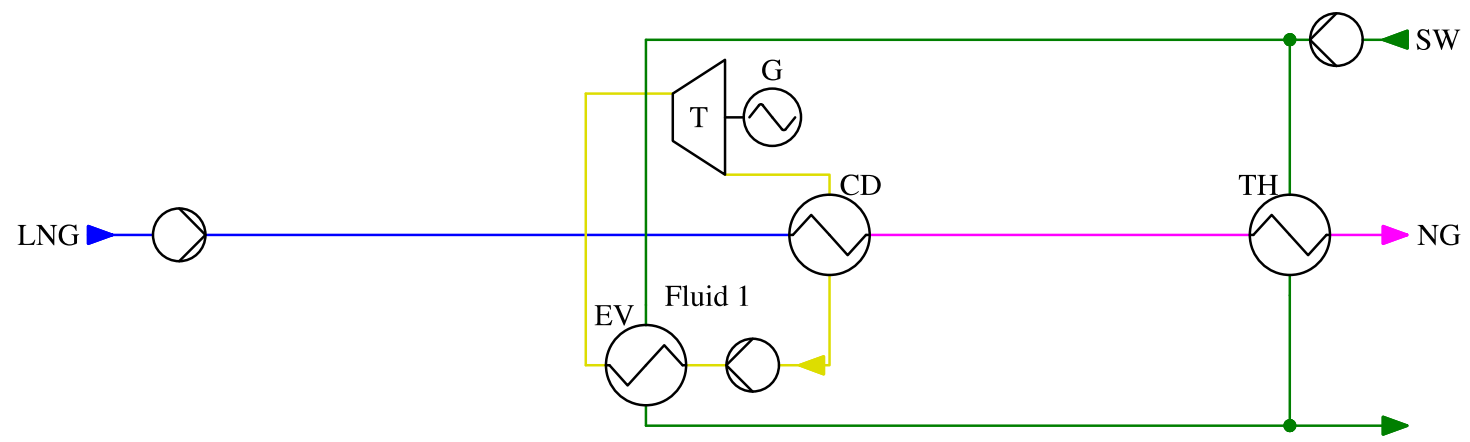

b)

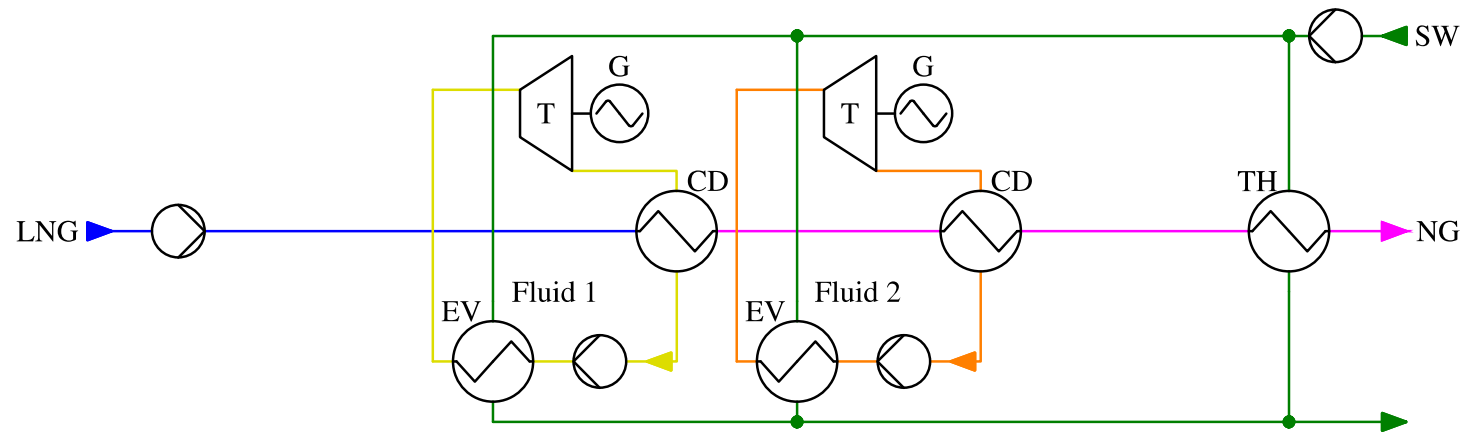

c)

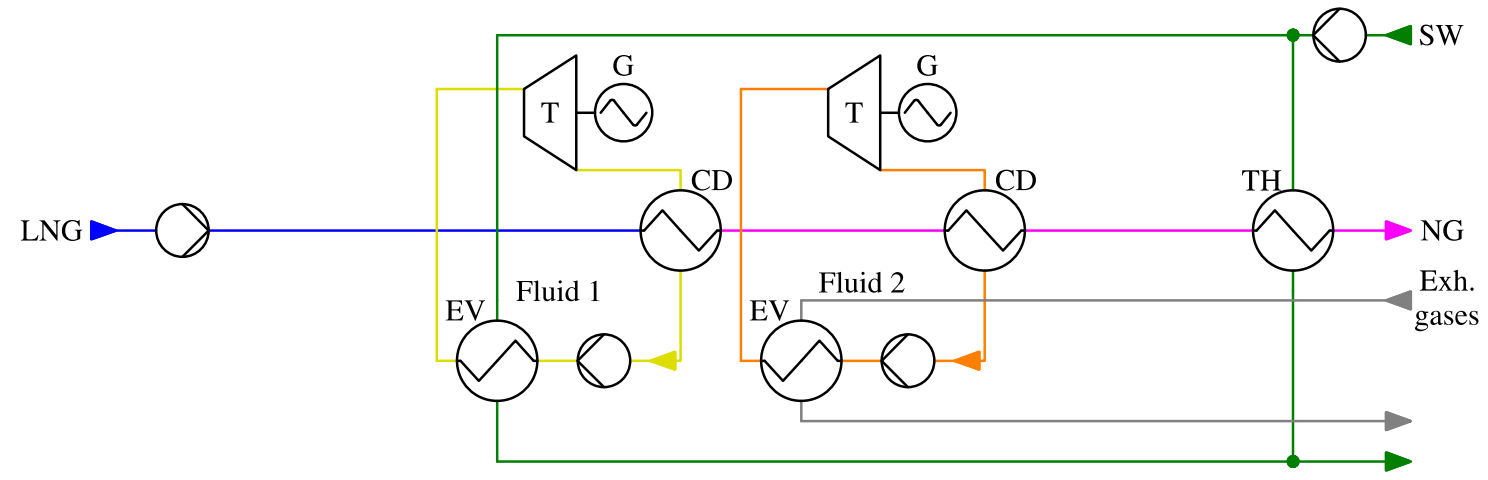

d)

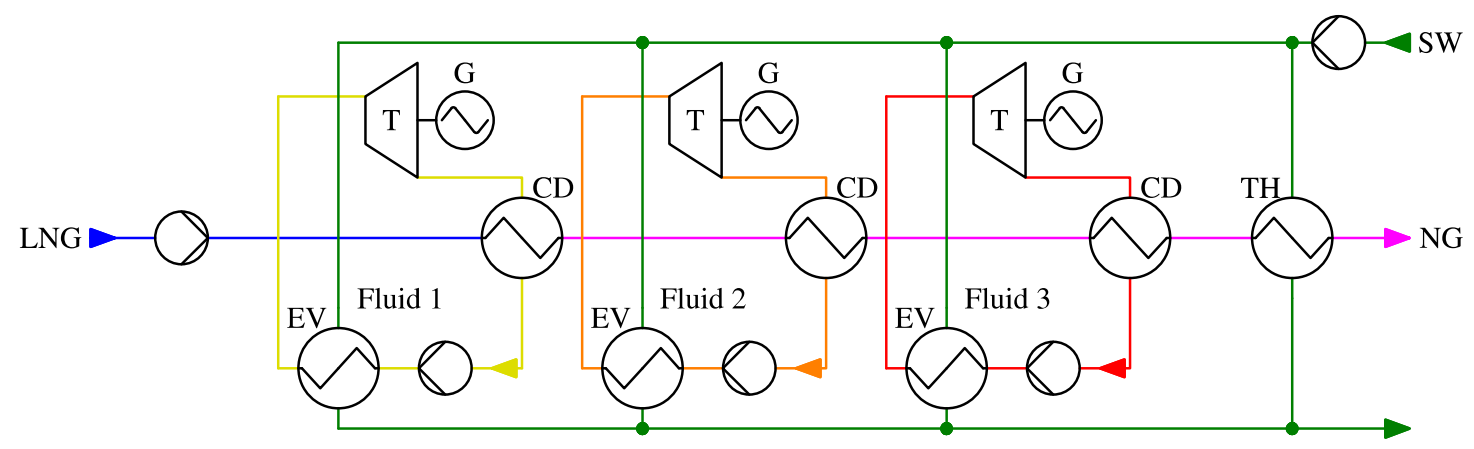

Fig. 11 Arrangement of ORCs in series: a) simple ORC (1-ORC), b) two-stage ORC (2-ORC), c) two-stage ORC with exhaust gases (2-ORC-EG), d) three-stage ORC (3-ORC) 
a)

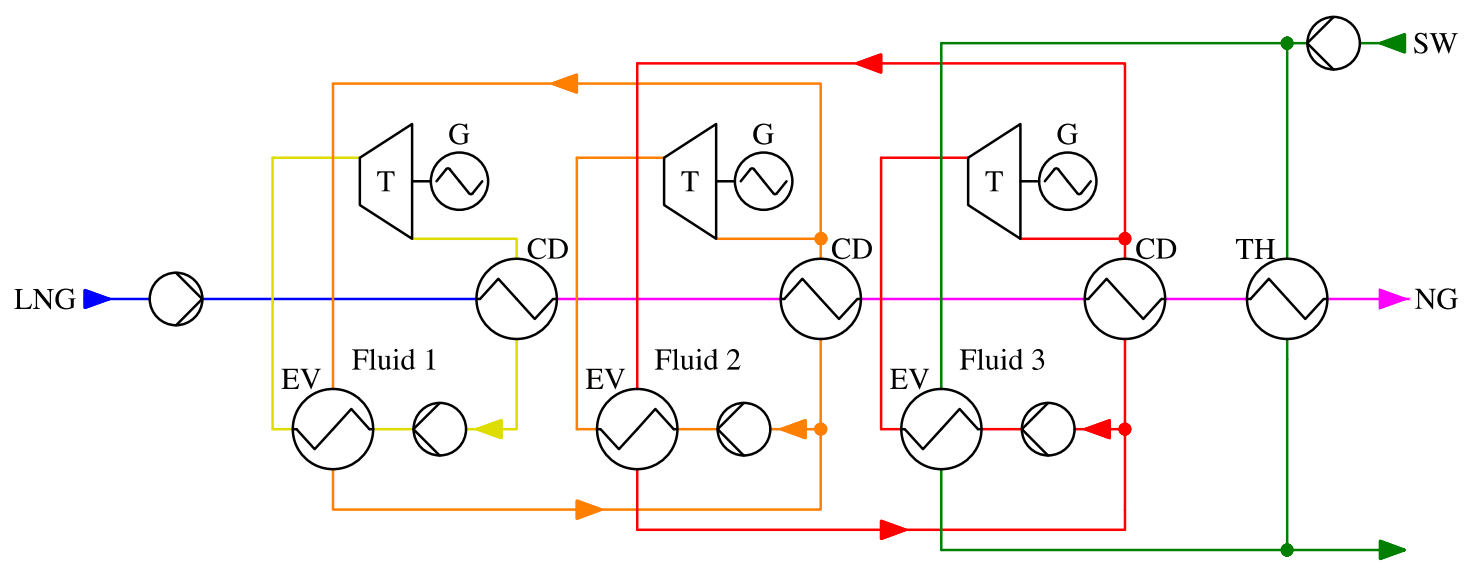

b)

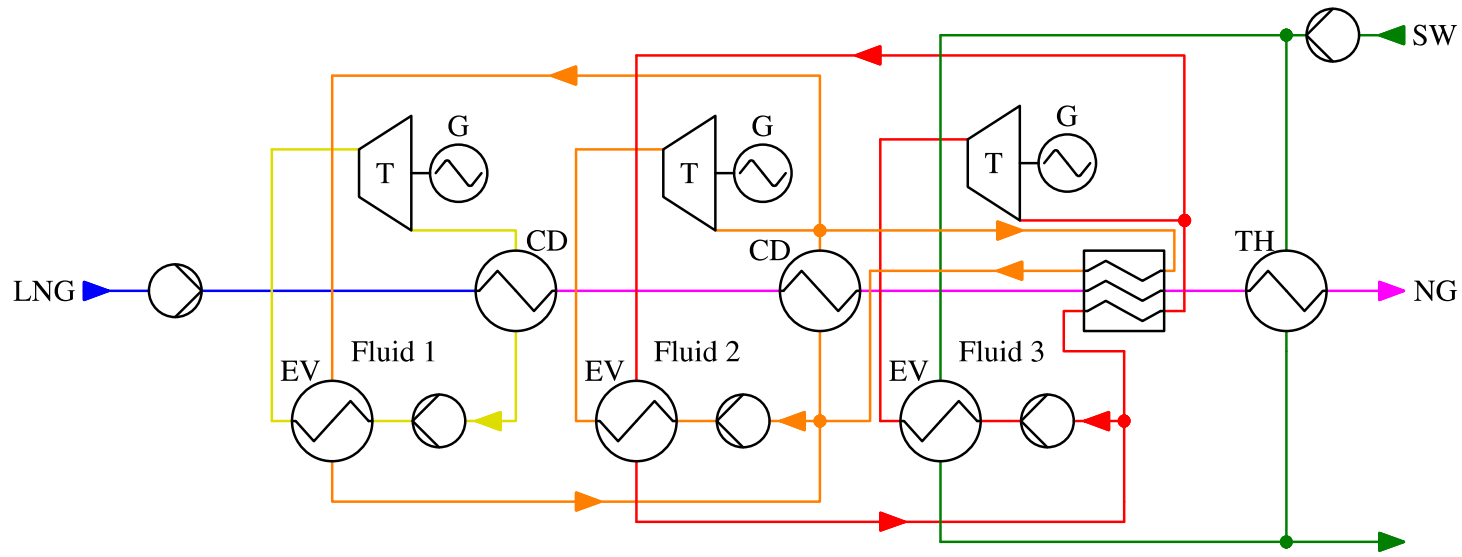

c)

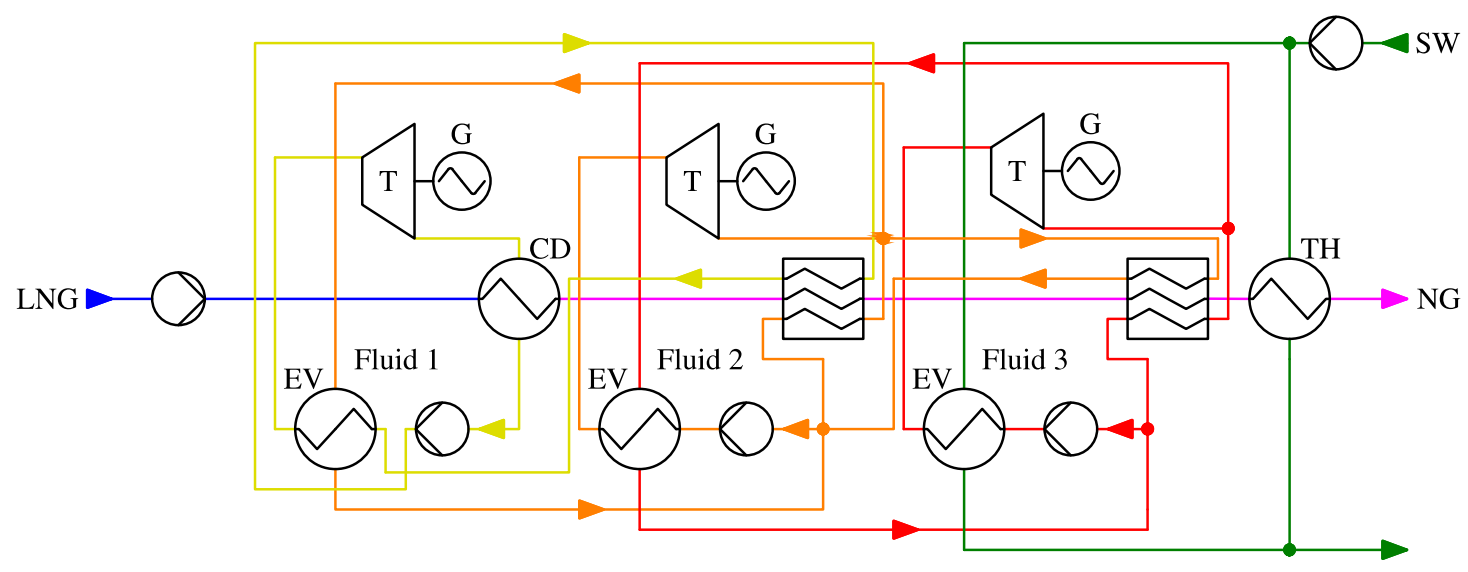

Fig. 12 Arrangement of ORCs in cascade: a) cascade three-level ORC (3-CRC), b) primary distributary cascade three-level ORC(PDCRC), c) secondary distributary cascade three-level ORC(SDCRC)

Yao et al. [55] perform an energy and exergy analysis of a simple ORC (1-ORC) with seawater as the heat source and LNG as the sink (Fig. 11a). Several working fluids are proposed with the aim of obtaining acceptable results: namely, propane, R143a, R152a, $\mathrm{NH}_{3}, \mathrm{R} 134 \mathrm{a}$ and propylene. Although the results suggest that propylene delivers best energy and exergy efficiency, the authors consider propane to be the ideal candidate due to the low vapor quality of propylene at the turbine outlet. The propane 1-ORC is subsequently improved with a twostage ORC (2-ORC), fitted with a second ORC with a lower condensing temperature (Fig. 11b). Three working fluids are analysed for the low temperature cycle: ethane, R23 and R116. Ethane 
delivers the best results, approximately doubling the thermal and exergy efficiency of the 2ORC with regards to the 1-ORC.

Lee et al. [56] assess three configurations: 1-ORC with propane (Fig. 11a), 2-ORC with propane in both cycles (Fig. 11b), and 2-ORC that includes the recovery of residual energy from the engine exhaust gases in the high temperature cycle (2-ORC-EG), as per Fig. 11c. Three working fluids are proposed for heat exchange with the exhaust gases: propane, R134a and R245fa. The 2-ORC-EG with propane achieves best results, increasing power production by $24 \%$ compared to the 1-ORC.

Yoon-Ho [57], based on the research performed by Yao et al. [55] and Lee et al. [56], studies the 1-ORC (Fig. 11a) and the 2-ORC (Fig. 11b) with zeotropic mixtures of ethane and propane. Besides carrying out an energy and exergy analysis, the study also conducts an economic analysis of the energy production cost and the annual savings engendered for each of the cases, according to the seawater temperature and the working fluid composition. The 1ORC, within a seawater temperature range of between $10{ }^{\circ} \mathrm{C}$ and $25^{\circ} \mathrm{C}$ and a mixture of $60 \%$ ethane and $40 \%$ propane, delivers better results than the cycle with pure propane. The 2-ORC with pure propane in the high-temperature cycle and a mixture of $80 \%$ ethane and $20 \%$ propane in the low-temperature cycle increases efficiencies by approximately $75 \%$ in comparison with the previous 1-ORC.

In another publication, Yoon-Ho [59] compares six configurations with pure fluids: 1ORC with propane (Fig. 11a); 2-ORC with propane and ethane (Fig. 11b); three-stage ORC (3ORC) with butane, propane and ethane (Fig. 11d); and the corresponding versions of each ORC in combination with a regasified NG direct expansion turbine, which only expands the NG flow consumed by dual fuel engines. This expansion is termed partial cold energy recovery (PaCER). Fig. 13 illustrates the difference between conventional direct expansion and PaCER. As in [57], an energy, exergy and economic study for each case is performed, achieving the best results from the 3-PaCER.

a)

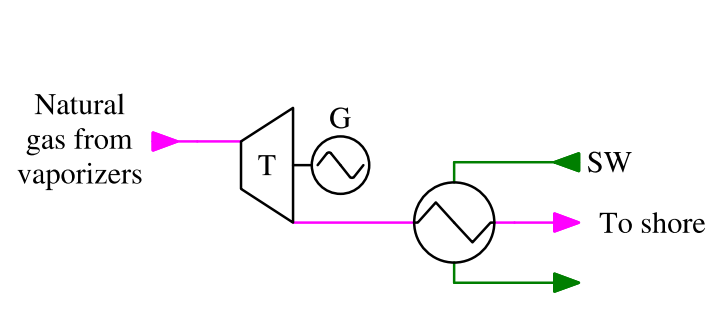

b)

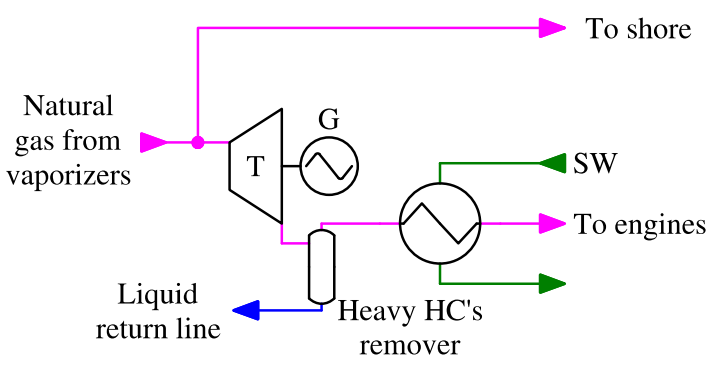

Fig. 13 Direct expansion systems: a) total expansion, b) partial expansion (PaCER)

Yao et al. [59] propose cascade ORCs as an alternative to ORCs in series to achieve greater exergy efficiency. Specifically, three configurations are assessed: cascade three-level ORC (3-CRC), primary distributary cascade three-level ORC (PDCR) and secondary distributary cascade three-level ORC (SDCR). Figs. 12a, 12b and 12c depict these cycles, respectively. Several working fluids are proposed: ethane, ethylene, propane, propylene and R23. Ethylene delivers best results in the low-temperature cycle, R23 in the intermediate cycle and propane in the high-temperature cycle. The SDCR obtains the highest exergy efficiency owing to the decrease of irreversibilities in the heat transfer processes.

Table A.2 gathers the most relevant data of the cycles proposed in the abovementioned papers, which are all based on open-loop systems: None address closed-loop regasification systems, despite being the most apt for the protection of the marine environment. 
It is also important to note that none of the studies consider the purpose of the regasification system, that is, the level of exploitation, or the effects of integrating these systems on the FSRU, particularly the electricity production equipment. The proposed working fluids are common among the papers and are usually hydrocarbons. It would be interesting to evaluate new, safer working fluids, pure or zeotropic mixtures. Similarly, the regasified NG flow rates used in the analyses are not typical values, this being especially important when carrying out the dimensioning and, therefore, the economic assessment.

With a view to the development of new offshore regasification projects, and the interest shown by companies and organizations related to the sector, it is imperative to propose new regasification systems that exploit the LNG cold energy to increase the efficiency of these vessels and reduce polluting gas emissions.

\section{Conclusions and future works}

This paper reviews the current technology of regasification systems in FSRUs and power cycles for the utilization of LNG cold energy, with the following conclusions being drawn:

- Regasification systems can be classified according to the heat source (open, closed or combined loop) and whether or not there is an intermediate fluid in the heat exchange process (indirect or direct). Open-loop systems use seawater as a heat source, while closed-loop use the steam generated in boilers. The choice of work loop must have the approval of the administration. If the use of seawater is not prohibited and the site temperature is suitable, systems capable of operating in open loop are normally installed.

- Closed-loop regasification systems (direct and indirect) offer a simple, compact, economical and maintenance-free design that is characterized by the use of noncorrosive fluids. This latter point enables all heat exchangers to be produced in conventional stainless steel. The water-glycol system reduces the risk of freezing when compared with the direct exchange steam system. The main drawback of these systems, however, is the high fuel consumption of the boilers in order to generate steam, hence, operational costs and harmful gas emissions -especially $\mathrm{CO}_{2}$ - are very high.

- In contrast, open-loop regasification systems provide a more efficient system but must deal with the inconvenience of seawater. If the heat exchange is direct, welded shell and tube heat exchangers made of titanium or corrosion-resistant stainless steels are fitted. The dimensioning and cost of materials significantly increases the cost of the regasification trains, but low fuel consumption offsets the initial investment. Only chemical cleaning is possible due to the installing of welded heat exchangers. Moreover, there is a risk of freezing inside the vaporizer.

- To eliminate the risk of seawater freezing, the most recommended regasification systems are those that use propane as an intermediate fluid. IFV is not the most suitable in FSRUs due to the volume required in its installation. In cases where space is limited, and there is no risk of the fluid freezing, the installation of PCHE-type vaporizers is considered most suitable. The propane regasification system comprising two PCHEs in series delivers a rather compact design and the plate heat exchangers can be disassembled to clean the sides in contact with seawater.

- Until recent years, seawater and propane were the most common regasification systems. Water-glycol systems, however, are currently cornering the market. The water-glycol mixture brings with it the risk of freezing, but is ultimately safer as it is non- flammable. Furthermore, it is low-cost and highly available. The vaporizer must 
be a shell-and-tube exchanger, but a downstream PCHE can be fitted providing the NG temperature is above the freezing temperature of the mixture, thus reducing the regasification train size. Measured against propane systems, it provides a simpler solution in which there are no phase-change processes or high pressure flammable intermediate fluids. However, the water-glycol mass flow is greater than that of propane, thereby requiring pumps of greater capacity and consumption.

- The energy and exergy analysis shows that LNG cold energy is the most significant residual energy source in an FSRU. The specific energy and exergy content is approximately double that of dual fuel engine exhaust gases. Even so, there are currently no FSRUs that exploit the cold energy potential of LNG.

- Depending on the level of exploitation of the cold energy available under normal regasification conditions, the electricity generated by the auxiliary power equipment (engines and steam turbines) can be reduced to zero and electric power can even be exported to land, thus significantly reducing $\mathrm{CO}_{2}$ emissions in FSRUs.

Scientific literature that addresses cold energy exploitation in FSRUs is very limited and focuses on the analysis of open-loop regasification systems with simple ORCs, and in-series or cascade configurations of different ORCs. None of the studies take into account the purpose of the regasification system: that is, the degree of exploitation or the impact of these systems on the FSRU, especially on the power generation plant. The proposal of efficient systems capable of operating in a closed loop, which has a lower impact on the eco system, is called for. In view of the need to reduce greenhouse gas emissions from vessels, the implementation of new regasification systems capable of exploiting the cold energy on board FSRUs is an interesting option for consideration. Future work by the authors is to focus on this line of research.

\section{ACKNOWLEDGMENTS}

The authors are grateful for the contribution of Per Helge Madsen in providing information about Wärtsilä's regasification systems.

\begin{tabular}{|llll|}
\hline \multicolumn{2}{ll}{ NOMENCLATURE } & SW & seawater \\
Abbreviations & TH & trim heater \\
BOG & boil off gas & USA & United States of America \\
BOR & boil off rate & VP & vaporizer \\
CAPEX & capital expenditure & WGH & water-glycol heater \\
DFDE & dual fuel diesel electric & Symbols & \\
DO & diesel oil & $\dot{E}$ & exergy flow rate $(\mathrm{kW})$ \\
EG & exhaust gases & $e$ & specific flow exergy $(\mathrm{kJ} / \mathrm{kg})$ \\
IEA & International Energy Agency & $h$ & energy flow rate $(\mathrm{kW})$ \\
FSRU & floating storage regasification & $\dot{H}$ & enthalpy $(\mathrm{kJ} / \mathrm{kg})$ \\
& unit & $p$ & mass flow rate $(\mathrm{kg} / \mathrm{s})$ \\
FSU & floating storage unit & $\dot{Q}$ & pressure $(\mathrm{bar})$ \\
GBS & gravity base structure & $S$ & heat transfer rate $(\mathrm{kW})$ \\
GCU & gas combustion unit & $T$ & entropy $(\mathrm{kJ} / \mathrm{kg}-\mathrm{K})$ \\
HP & high pressure & $\dot{W}$ & temperature $\left({ }^{\circ} \mathrm{C}\right)$ \\
LD & compressor low duty & $\eta$ & power $(\mathrm{kW})$ \\
& & & efficiency $(-)$ \\
\hline
\end{tabular}




\begin{tabular}{|llll|}
\hline LHV & lower heating value & Subscripts and Superscripts \\
LNG & liquefied natural gas & 0 & reference condition \\
MX & mixer & ex & exergy \\
R & recondenser & $\mathrm{n}$ & net \\
RS & regasification system & $\mathrm{p}$ & pressure \\
S & separator & ph & physical \\
SRV & shuttle regasification vessel & th & thermal \\
STS & ship to ship & & \\
\hline
\end{tabular}

\section{REFERENCES}

[1] International Energy Agency. World Energy Outlook 2020. 2020.

[2] International Energy Agency. World Energy Outlook 2020 Executive Summary. 2020.

[3] International Energy Agency. World Energy Outlook 2019. 2019.

[4] Mokhatab S, Mak JY, Valappil J V., Wood DA. Handbook of Liquefied Natural Gas. Elsevier; 2014. https://doi.org/10.1016/C2011-0-07476-8.

[5] IMO. MEPC.304(72) Initial IMO Strategy on Reduction of GHG Emissions from Ships 2018.

[6] Havard D. Oil and Gas Production Handbook: An introduction to oil and gas production, transport, refining and petrochemical industry. ABB; 2013.

[7] Speight JG. Natural Gas: A Basic Handbook. Second Edi. Gulf Professional Publishing; 2019. https://doi.org/10.1016/C2015-0-02190-6.

[8] Mokhatab S, Poe WA, Mak JY. Handbook of natural gas transmission and processing: Principles and practices. Oxford: Elsevier; 2018. https://doi.org/10.1016/C2017-0-03889-2.

[9] Norrgård J. LNG terminals - land-based vs. floating storage and regasification technology. Wärtsilä Tech J 2018.

[10] Songhurst B. The Outlook for Floating Storage and Regasification Units (FSRUs). Oxford, United Kingdom: 2017. https://doi.org/https://doi.org/10.26889/9781784670894.

[11] Tusiani, Michael D; Shearer G. LNG: A Nontechnical Guide. PennWell; 2007.

[12] Park S, Kim S, Yoon Y, Lee IB, Jung ES. A comparative evaluation of heating method options for floating storage regasification units using life cycle cost analysis with risk expenditure. J Chem Eng Japan 2019;52:751-65. https://doi.org/10.1252/jcej.18we124.

[13] Romero Gómez M, Ferreiro Garcia R, Romero Gómez J, Carbia Carril J. Review of thermal cycles exploiting the exergy of liquefied natural gas in the regasification process. Renew Sustain Energy Rev 2014;38:781-95. https://doi.org/10.1016/j.rser.2014.07.029.

[14] Kanbur BB, Xiang L, Dubey S, Choo FH, Duan F. Cold utilization systems of LNG: A review. Renew Sustain Energy Rev 2017;79:1171-88. https://doi.org/10.1016/j.rser.2017.05.161.

[15] Mehrpooya M, Sharifzadeh MMM, Katooli MH. Thermodynamic analysis of integrated LNG regasification process configurations. Prog Energy Combust Sci 2018;69:1-27. https://doi.org/10.1016/j.pecs.2018.06.001.

[16] He T, Chong ZR, Zheng J, Ju Y, Linga P. LNG cold energy utilization: Prospects and challenges. Energy 2019;170:557-68. https://doi.org/10.1016/j.energy.2018.12.170.

[17] Pospíšil J, Charvát P, Arsenyeva O, Klimeš L, Špiláček M, Klemeš JJ. Energy demand of liquefaction and regasification of natural gas and the potential of LNG for operative thermal energy storage. Renew Sustain Energy Rev 2019;99:1-15. https://doi.org/10.1016/j.rser.2018.09.027.

[18] Janssens P. The development of the first Energy Bridge regasification vessel. Offshore Technol Conf 2006 New Depths New Horizons 2006;3:2052-63. https://doi.org/10.4043/18398-ms.

[19] Larsen OB, Markussen BK. SRV - The LNG Shuttle and Regas Vessel System. Proc Annu Offshore Technol Conf 2004;2:1078-81. https://doi.org/10.4043/16580-ms.

[20] Wärtsilä. Wärtsilä 2020. https://www.wartsila.com/ (accessed November 23, 2020). 
Manuel Naveiro, Manuel Romero Gómez,

Ignacio Arias Fernández, Javier Romero Gómez
Exploitation of liquefied natural gas cold energy in Floating Storage Regasification Units

[21] Fernández IA, Gómez MR, Gómez JR, Insua ÁB. Review of propulsion systems on LNG carriers. Renew Sustain Energy Rev 2017;67:1395-411. https://doi.org/10.1016/j.rser.2016.09.095.

[22] Ammar NR. Environmental and cost-effectiveness comparison of dual fuel propulsion options for emissions reduction onboard lng carriers. Brodogradnja 2019; 70:61-77. https://doi.org/10.21278/brod70304.

[23] Equasis. Equasis - HomePage 2020. https://www.equasis.org/EquasisWeb/public/HomePage (accessed November 11, 2020).

[24] Clarksons. Clarksons Research Portal 2020. https://www.clarksons.net/Portal/ (accessed November 11, 2020).

[25] KARPOWERSHIP. KARPOWERSHIP 2020. http://www.karpowership.com/en/ (accessed November 11, 2020).

[26] Wood DA, Kulitsa M. A review: Optimizing performance of Floating Storage and Regasification Units (FSRU) by applying advanced LNG tank pressure management strategies. Int J Energy Res 2018;42:1391418. https://doi.org/10.1002/er.3883.

[27] Dobrota Đ, Lalić B, Komar I. Problem of Boil - off in LNG Supply Chain. Trans Marit Sci 2013;2:91-100. https://doi.org/10.7225/toms.v02.n02.001.

[28] Maksym K, David AW. Floating storage and regasification units face specific LNG rollover challenges: Consideration of saturated vapor pressure provides insight and mitigation options. Nat Gas Ind B 2018;5:391-414. https://doi.org/10.1016/j.ngib.2018.05.001.

[29] Lloyd's Register. Floating Storage and Regasification Units. 2017.

[30] Samsung Heavy Industries. S-REGAS Regasification System (Brochure) 2014.

[31] Hyundai Heavy Industries. ENGINE \& MACHINERY DIVISION HHI-EMD (Brochure) 2018.

[32] Sulzer. Sulzer 2020. https://www.sulzer.com/ (accessed November 23, 2020).

[33] Madsen, Per Helge Sandaroe; Lunde T. Regasification modules for onboard applications offer multiple benefits. Wärtsilä Tech J 2012:31-8.

[34] Cryostar. Cryostar 2020. https://cryostar.com/ (accessed November 23, 2020).

[35] NEUMAN \& ESSER. NEUMAN \& ESSER - Compressors for industrial use 2020. https://www.neumanesser.de/en/ (accessed November 12, 2020).

[36] Compression B. Home - Burckhardt Compression 2020. https://www.burckhardtcompression.com/ (accessed November 14, 2020).

[37] Excelerate Energy. Excelerate Energy - Pioneer and Leader in Floating Regas 2020. https://excelerateenergy.com/ (accessed November 23, 2020).

[38] Höegh LNG. Höegh LNG 2020. https://hoeghlng.com/ (accessed November 23, 2020).

[39] Madsen PHS, Karsten D, Strande R. Intermediate fluid vaporizers for LNG re-gasification vessels, SRVs and FSRU's. Proc Annu Offshore Technol Conf 2010;3:2185-98. https://doi.org/10.4043/20809-ms.

[40] Excelerate Energy. Floating Storage Regasification Unit (FSRU) - Excelerate Energy 2020. https://excelerateenergy.com/fsru/ (accessed July 2, 2020).

[41] U.S. Coast Guard; engineering-environmental Management. Neptune LNG Deepwater Port License Application: Environmental Impact Statement. 2006.

[42] Exmar Shipmanagement. Best Practices in the disposal of ships' waste. 2010.

[43] Moss Maritime. A Leader In Maritime Technology (General Brochure) n.d.

[44] Blackwell B, Skaar H. GOLAR LNG: DELIVERING THE WORLD'S FIRST FSRUs. 24th World Gas Conf 2009.

[45] Entec D. HP Vaporizer for RV/FSRU- DongHwa Entec : Marine Products 2020. http://www.dh.co.kr/hpvaporizer-rvfsru/?ckattempt=1 (accessed September 7, 2020).

[46] Egashira S. LNG vaporizer for LNG re-gasification terminal. R D Res Dev Kobe Steel Eng Reports 2013;63:33-6.

[47] Kobe Steel Ltd. LNG Vaporizers on FSRU: Intermediate Fluid Vaporizer 2019.

[48] Eum Y, Kim S, Doh K, Ha M. Eco-friendly LNG SRV: Completion of the regas trial. Int Gas Res Conf Proc 2011;4:2791-803.

[49] Madsen PH. A PLANT AND METHOD FOR REGASIFICATION OF LNG. WO 2017/095230 Al, 2017.

[50] Cryostar. Equipment and Solutions LNG / NG STARVAP TM REGASIFICATION APPLICATIONS THE CRYOSTAR GROUP n.d. 
[51] Frangopoulos CA. Exergy, Energy System Analysis and Optimization Volume - I: Exergy and Thermodynamic Analysis. Oxford, United Kingdom: EOLSS Publications; 2009.

[52] Wärtsilä. Wärtsilä 50DF product guide 2018.

[53] Mitsui O.S.K. Lines. MOL and DSME Obtain AIP for Design of FSRU “Cryo-Powered Regas” System Development of New Technology to Reduce Environmental Impact - 2020.

[54] Mitsui O.S.K. Lines. FSRU (Floating Storage and Regasification Unit) 2020. https://www.molservice.com/service/fsru (accessed December 1, 2020).

[55] Yao S, Liu H, Tang L, Ye Y, Zhang L. Thermodynamic analysis and optimization for cold energy utilization based on low temperature rankine cycle of LNG-FSRU regasification system. Int J Simul Syst Sci Technol 2016;17:35.1-35.9. https://doi.org/10.5013/IJSSST.a.17.30.35.

[56] Lee S, Choi BC. Thermodynamic assessment of integrated heat recovery system combining exhaust-gas heat and cold energy for LNG regasification process in FSRU vessel. J Mech Sci Technol 2016;30:1389_ 98. https://doi.org/10.1007/s12206-016-0246-y.

[57] Yoon-Ho L. LNG-FSRU cold energy recovery regasification using a zeotropic mixture of ethane and propane. Energy 2019;173:857-69. https://doi.org/10.1016/j.energy.2019.02.111.

[58] Yoon-Ho L. Thermo-economic analysis of a novel regasification system with liquefied-natural-gas coldenergy. Int J Refrig 2019;101:218-29. https://doi.org/10.1016/j.ijrefrig.2019.03.022.

[59] Yao S, Xu L, Tang L. New cold-level utilization scheme for cascade three-level Rankine cycle using the cold energy of liquefied natural gas. Therm Sci 2018;2018:3865-75. https://doi.org/10.2298/TSCI171012239Y. 
Manuel Naveiro, Manuel Romero Gómez,

Ignacio Arias Fernández, Javier Romero Gómez
Exploitation of liquefied natural gas cold energy in Floating Storage Regasification Units

\section{APPENDIX A}

Table A.1 FSRU fleet list at the end of 2020

\begin{tabular}{|c|c|c|c|c|c|c|c|c|c|}
\hline 氞 & 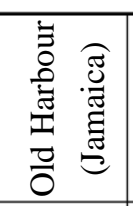 & 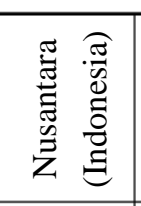 & 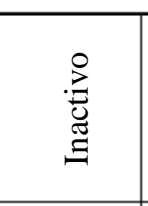 & 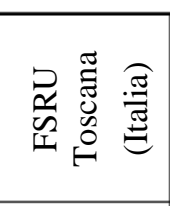 & 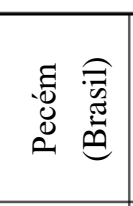 & 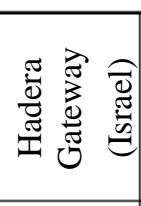 & 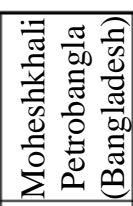 & 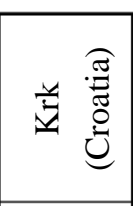 & 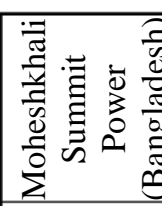 \\
\hline U & 文 & 亥 & 主 & $\underset{a}{\mathbb{z}}$ & 主 & 票 & 糹 & 主 & 方 \\
\hline 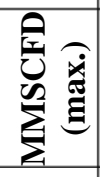 & 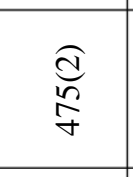 & 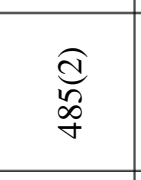 & 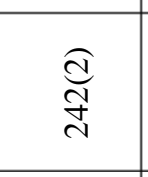 & 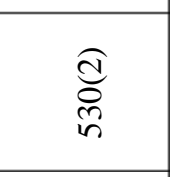 & $\begin{array}{l}\widehat{d} \\
\text { ¿ } \\
i n\end{array}$ & 8 & 8 & นุ & 8 \\
\hline 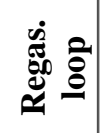 & 0 & 0 & U & 0 & $\frac{0}{0}$ & $\underset{0}{U_{0}}$ & $\underset{0}{\bigcup_{0}}$ & $\underbrace{\bar{U}}_{0} 0$ & $\underbrace{}_{0} 0$ \\
\hline$\dot{0}$ & $\underset{\Xi}{\tilde{\varpi}}$ & 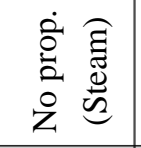 & 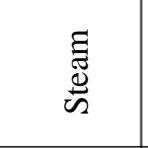 & 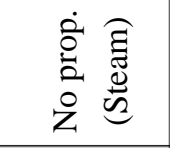 & 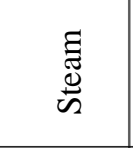 & 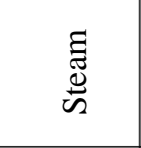 & 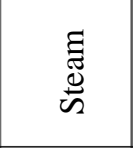 & 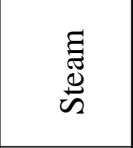 & 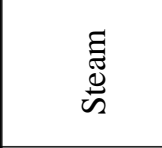 \\
\hline 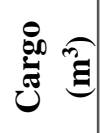 & $\begin{array}{l}8 \\
8 \\
\ddots 1 \\
1\end{array}$ & $\begin{array}{l}8 \\
8 \\
1 \\
1\end{array}$ & $\begin{array}{l}8 \\
8 \\
\grave{1}\end{array}$ & $\begin{array}{l}8 \\
\stackrel{n}{n} \\
\text { n }\end{array}$ & $\begin{array}{l}8 \\
8 \\
\infty \\
\infty \\
\end{array}$ & 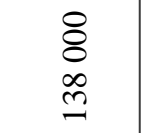 & $\begin{array}{l}8 \\
8 \\
\infty \\
\end{array}$ & $\begin{array}{l}8 \\
8 \\
\&\end{array}$ & $\begin{array}{l}8 \\
8 \\
\infty \\
\infty\end{array}$ \\
\hline$\stackrel{\frac{\pi}{\tilde{E}}}{\tilde{E}}$ & $\stackrel{0}{n}^{\infty}$ & 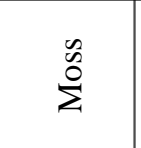 & $\sum^{\infty}$ & $\stackrel{\omega}{\tilde{\Sigma}}^{\tilde{c}}$ & $\begin{array}{l}\text { \& } \\
\text { Z }\end{array}$ & $\begin{array}{l}\text { ò } \\
\text { z }\end{array}$ & $\begin{array}{l}\text { o̊ } \\
\text { Z }\end{array}$ & 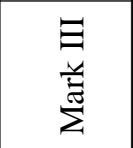 & oి \\
\hline 它 & $\underset{\partial}{\stackrel{0}{0}}$ & 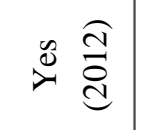 & is & 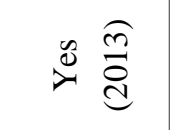 & 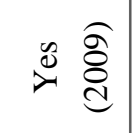 & $\stackrel{\circ}{z}$ & $\stackrel{\circ}{z}$ & ¿ & $\stackrel{\circ}{z}$ \\
\hline$\ddot{\Xi}$ & $\stackrel{0}{2}$ & 令 & $\vec{\infty}$ & ষ্ণ & ఫ্ণ & ڤి & ڤి & ڤి & ఫ્ڤ \\
\hline 晜 & $\begin{array}{l}\overline{\mathrm{d}} \\
\overline{\vec{v}} \\
\bar{v}\end{array}$ & 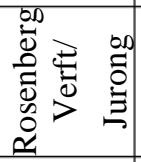 & 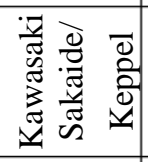 & 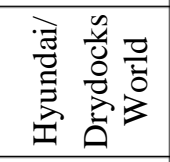 &  & 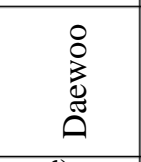 & $\begin{array}{l} \\
8 \\
0 \\
0 \\
0 \\
\\
\end{array}$ & 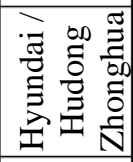 & 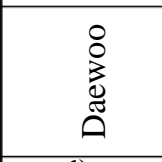 \\
\hline bे & 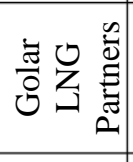 & 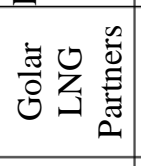 & 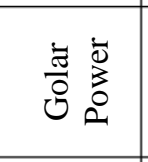 & 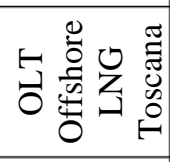 & 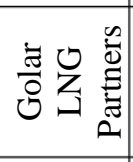 & 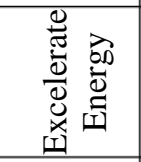 & 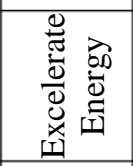 & 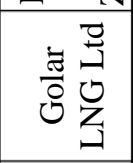 & 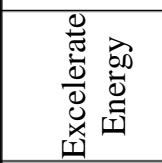 \\
\hline$\stackrel{0}{i}$ & 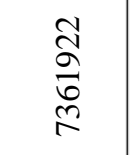 & 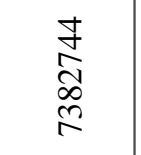 & 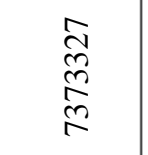 & 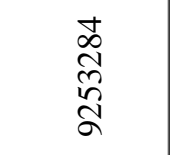 & $\begin{array}{l}\frac{ \pm}{8} \\
\stackrel{d}{a} \\
\sigma\end{array}$ & 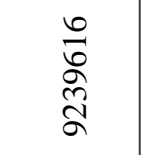 & $\begin{array}{l}\hat{2} \\
\text { ñ } \\
\hat{n} \\
\tilde{\sigma}\end{array}$ & 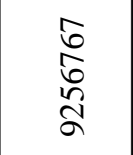 & 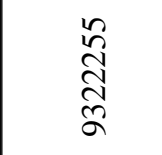 \\
\hline 节 & 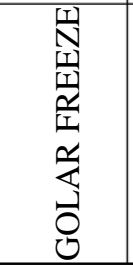 & 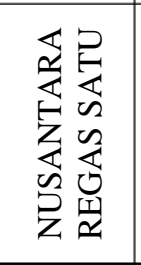 & 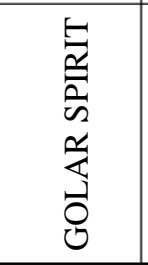 & 焉 & 采峦 & 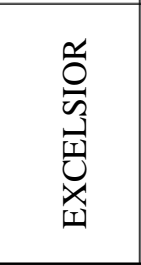 & 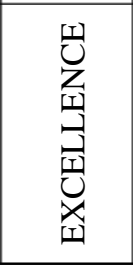 & 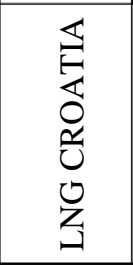 & 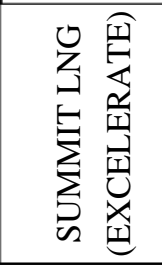 \\
\hline
\end{tabular}


Table A.1 FSRU fleet list at the end of 2020 (cont.)

\begin{tabular}{|c|c|c|c|c|c|c|c|c|c|c|c|}
\hline 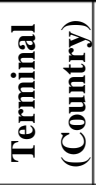 & 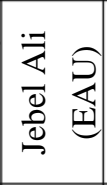 & 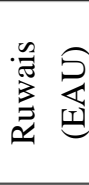 & (్) & 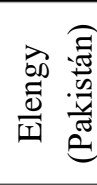 & (2) & 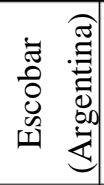 & 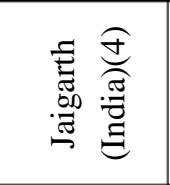 & $\widehat{\approx}$ & 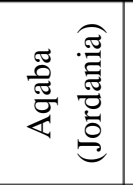 & 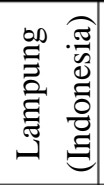 & 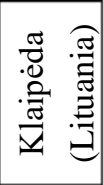 \\
\hline 己 & 㐫 & 分 & 忩 & 分 & 忩 & 㐫 & 忩 & 分 & 忩 & 忩 & 文 \\
\hline 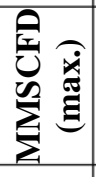 & \& & 8̊ & ' & 8 & $\stackrel{\circ}{n}$ & 8 & $\stackrel{\Re}{n}$ & 8ి & $\stackrel{\circ}{n}$ & ষ্ণ & $\underset{\substack{+m}}{+}$ \\
\hline 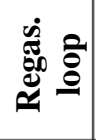 & $\frac{0}{0} 0$ & $\frac{0}{0}$ & $\underset{0}{\overparen{E}}$ & $\underbrace{0}_{0} 0$ & U & $\frac{0}{0} 0$ & U & $\frac{0}{0} 0$ & 0 & 0 & $\frac{0}{0} 0$ \\
\hline$\dot{0}$ & 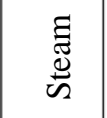 & 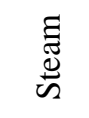 & 䐩 & 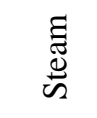 & 䆓 & 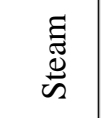 & 䆓 & 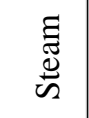 & 䐩 & 鬲 & 㭊 \\
\hline : & \begin{tabular}{l}
8 \\
8 \\
2 \\
\hdashline
\end{tabular} & $\begin{array}{l}8 \\
8 \\
i \\
1\end{array}$ & \begin{tabular}{l}
$\stackrel{8}{+}$ \\
\multirow{6}{\sigma}{} \\
-
\end{tabular} & $\begin{array}{l}8 \\
8 \\
i \\
1\end{array}$ & $\frac{\stackrel{9}{n}}{\stackrel{n}{ \pm}}$ & $\begin{array}{l}8 \\
8 \\
\circ \\
1\end{array}$ & $\begin{array}{l}\stackrel{一}{n} \\
\stackrel{n}{J}\end{array}$ & $\begin{array}{l}8 \\
8 \\
8 \\
2\end{array}$ & \begin{tabular}{l}
8 \\
8 \\
8 \\
\hdashline
\end{tabular} & 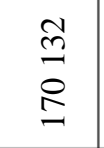 & $\begin{array}{l}8 \\
8 \\
ং \\
-\end{array}$ \\
\hline 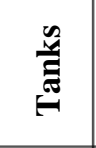 & $\begin{array}{l}\text { ̊े } \\
\text { Z }\end{array}$ & $\begin{array}{l}\text { o̊ } \\
\text { రి }\end{array}$ & $\begin{array}{l}\text { ஜ̊ } \\
\text { ○े }\end{array}$ & $\begin{array}{l}\text { o̊ } \\
\text { ○े }\end{array}$ & 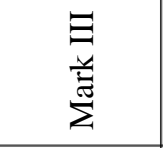 & $\begin{array}{l}\text { \&̊ } \\
\text { ○े }\end{array}$ & 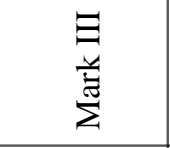 & $\begin{array}{l}8 \\
\text { ò } \\
z\end{array}$ & $\begin{array}{l}\text { 亲 } \\
\frac{\bar{i}}{\Sigma}\end{array}$ & $\begin{array}{l}\text { 严 } \\
\sum \\
\sum\end{array}$ & 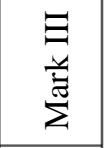 \\
\hline $\begin{array}{l}\dot{\vec{\Xi}} \\
\dot{\vec{\Xi}}\end{array}$ & $\stackrel{\circ}{z}$ & $\stackrel{\circ}{z}$ & 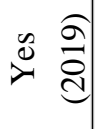 & ż & $\stackrel{\circ}{z}$ & $\stackrel{\circ}{z}$ & $\stackrel{2}{z}$ & $\stackrel{2}{z}$ & $\stackrel{\circ}{z}$ & $\stackrel{\circ}{z}$ & z \\
\hline 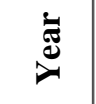 & 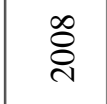 & ڤ્ळे & ठे & ठे & ठे & $\stackrel{\circ}{\stackrel{2}{\circ}}$ & $\stackrel{\circ}{\stackrel{\circ}{\circ}}$ & $\stackrel{\circ}{\circ}$ & $\frac{\Delta}{\stackrel{d}{c}}$ & $\frac{\Delta}{\stackrel{d}{d}}$ & $\frac{\Delta}{\stackrel{\sim}{\circ}}$ \\
\hline 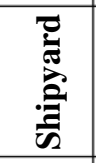 & 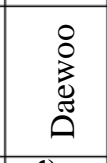 & 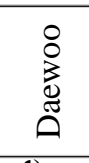 & 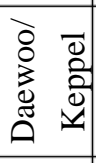 & 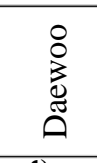 & 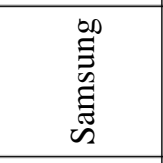 & 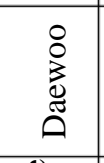 & 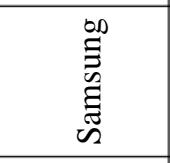 & 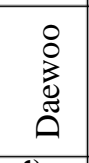 & 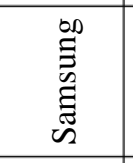 & 离 & 苞 \\
\hline 童 & 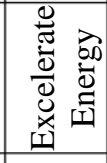 & 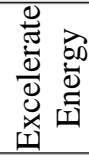 & 主 & 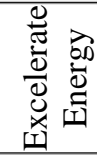 & 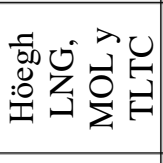 & 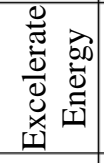 & 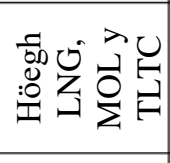 & 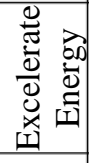 & $\begin{array}{lll}0 & 0 \\
0 & 0 & 0 \\
0 & \vdots \\
0 & \vdots \\
0\end{array}$ & $\begin{array}{l}50 \\
800 \\
00 \\
0 \\
0\end{array}$ &  \\
\hline$\stackrel{O}{\stackrel{Q}{i}}$ & $\begin{array}{l}\hat{\sigma} \\
\frac{\sigma}{0} \\
\sigma\end{array}$ & 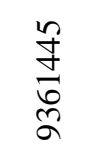 & $\begin{array}{l}1 \\
\delta \\
\infty \\
0 \\
0 \\
\sigma\end{array}$ & $\begin{array}{l}\stackrel{ \pm}{m} \\
\stackrel{\infty}{\sigma} \\
\sigma\end{array}$ & 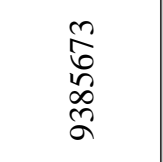 & $\begin{array}{l}\text { đa } \\
\stackrel{0}{\alpha} \\
\sigma\end{array}$ & 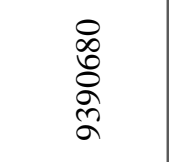 & $\begin{array}{l}\text { 导 } \\
\text { 寺 } \\
\text { d }\end{array}$ & 京 & 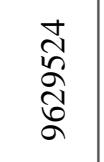 & 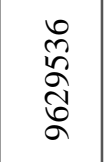 \\
\hline 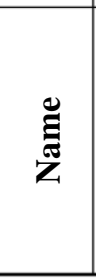 & 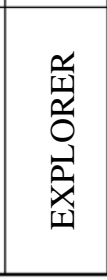 & 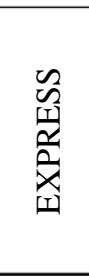 & $\begin{array}{l}\frac{n}{2} \\
\frac{2}{2} \\
z \\
\infty \\
\infty\end{array}$ & 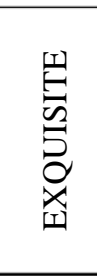 & 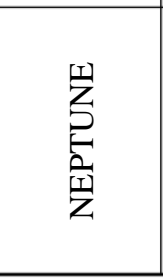 & 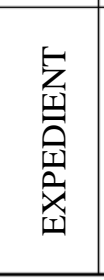 & 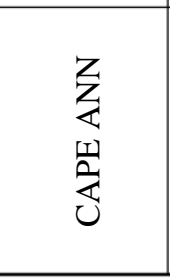 & 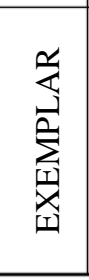 & 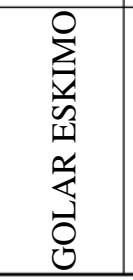 & 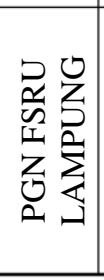 & 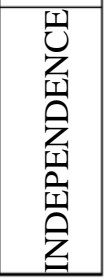 \\
\hline
\end{tabular}


Manuel Naveiro, Manuel Romero Gómez,

Ignacio Arias Fernández, Javier Romero Gómez
Exploitation of liquefied natural gas cold energy in Floating Storage Regasification Units

Table A.1 FSRU fleet list at the end of 2020 (cont.)

\begin{tabular}{|c|c|c|c|c|c|c|c|c|c|c|c|}
\hline 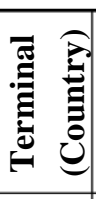 & 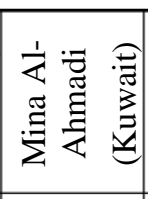 & 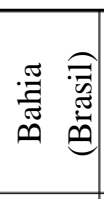 & $\widehat{(0)}$ & $\widehat{(0)}$ & 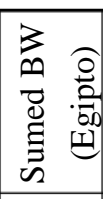 & 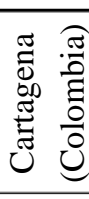 & 离苇 & 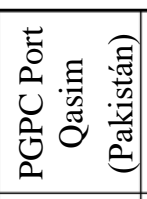 & $\widehat{(0)}$ & 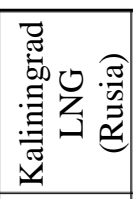 & 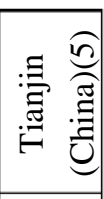 \\
\hline 己 & 文 & $\vec{m}$ & 文 & 文 & 文 & 文 & 㐫 & 文 & 亥 & $\approx \cong$ & 文 \\
\hline 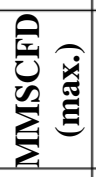 & $\stackrel{R}{n}$ & $\underset{\infty}{\infty}$ & 8 & iㅗ & in & 8 & đ্d & in & in & & $\stackrel{i}{n}$ \\
\hline 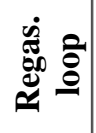 & 0 & $\frac{\underbrace{}_{0}}{\bar{U}_{0}}$ & 0 & 0 & 0 & 0 & $\stackrel{\Xi}{\Xi}$ & 0 & 0 & $\frac{D_{0}}{U_{0}}$ & $\frac{\hat{U}_{0}}{0}$ \\
\hline$\dot{\stackrel{\Delta}{0}}$ & 劉 & 壹 & 窖 & 荘 & 耑 & 㭊 & 䝁 & 莞 & 耑 & 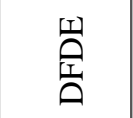 & 荘 \\
\hline 苞 & \begin{tabular}{l}
8 \\
$\&$ \\
\hdashline
\end{tabular} &  & 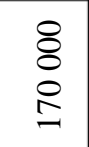 & $\begin{array}{l}8 \\
8 \\
ং \\
1\end{array}$ & \begin{tabular}{l}
8 \\
8 \\
2 \\
\hdashline
\end{tabular} & $\begin{array}{l}8 \\
8 \\
8 \\
1\end{array}$ & 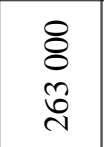 & $\begin{array}{l}8 \\
8 \\
8 \\
1\end{array}$ & $\begin{array}{l}8 \\
8 \\
8 \\
1\end{array}$ & $\begin{array}{l}8 \\
8 \\
\pm \\
1\end{array}$ & 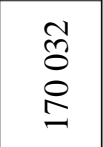 \\
\hline 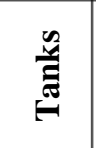 & 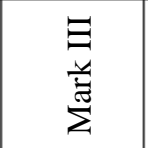 & $\begin{array}{l}\text { \& } \\
\text { Z }\end{array}$ & 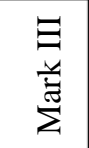 & 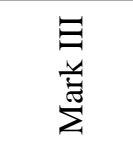 & 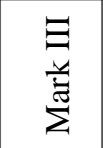 & $\begin{array}{l}\exists \\
\text { 亲 } \\
\sum\end{array}$ & $\begin{array}{l}\text { \& } \\
\text { o } \\
z\end{array}$ & 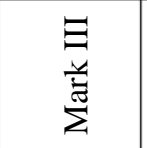 & $\begin{array}{l}\text { 目 } \\
\text { 竝 }\end{array}$ & 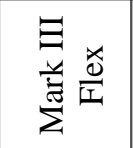 & 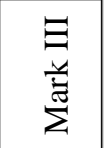 \\
\hline 离 & ż & z & z & ż & z & z & ż & z & z & $\ddot{z}$ & $\stackrel{2}{z}$ \\
\hline$\ddot{\Xi}$ & $\stackrel{\Delta}{\stackrel{d}{d}}$ & $\stackrel{\vec{d}}{\stackrel{d}{d}}$ & $\stackrel{\vec{d}}{\stackrel{\sim}{d}}$ & $\stackrel{n}{\stackrel{n}{d}}$ & $\stackrel{n}{\stackrel{n}{d}}$ & $\stackrel{0}{\stackrel{7}{\pi}}$ & $\stackrel{ }{\bar{c}}$ & $\stackrel{ }{\vec{i}}$ & $\stackrel{ }{\vec{i}}$ & $\stackrel{\infty}{\stackrel{\infty}{i}}$ & $\stackrel{\infty}{\stackrel{\sim}{\sim}}$ \\
\hline 离 & 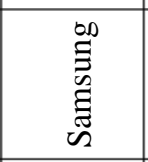 & $\begin{array}{l}8 \\
\vdots \\
0 \\
0 \\
0\end{array}$ & 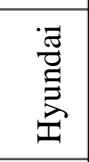 & 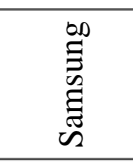 & 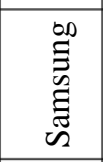 & 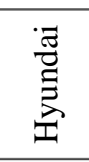 & $\begin{array}{l}8 \\
8 \\
3 \\
0 \\
0 \\
0\end{array}$ & 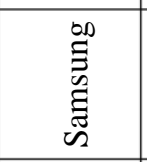 & 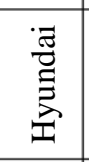 & 吾 & 苞 \\
\hline 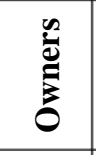 & 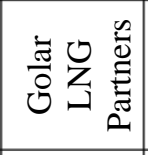 & 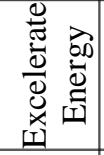 & 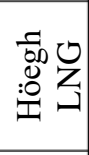 & 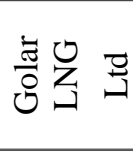 & 会 & 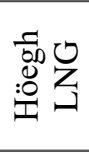 & $\stackrel{\overrightarrow{0}}{\Sigma}$ & 営 & 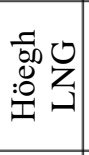 & 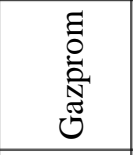 & 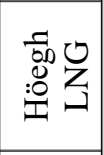 \\
\hline$\stackrel{0}{i}$ & $\begin{array}{l}\bar{\sigma} \\
\text { बूँ }\end{array}$ & 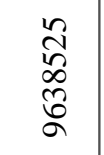 & 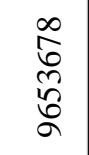 & $\begin{array}{l}\infty \\
\infty \\
\infty \\
20 \\
2\end{array}$ & 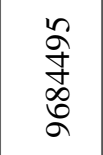 & 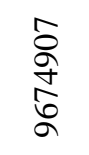 & $\frac{\stackrel{n}{a}}{\frac{a}{a}}$ & 京 & $\begin{array}{l}\text { तू } \\
\text { సু } \\
\text { ลू }\end{array}$ & 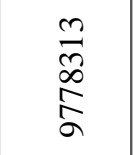 & 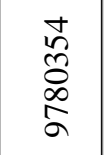 \\
\hline 䒕 & 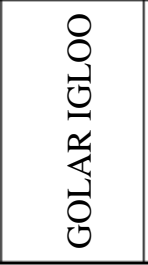 & 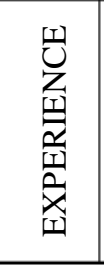 & 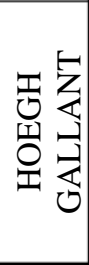 & 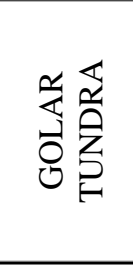 & $\begin{array}{l}1 \\
0 \\
0 \\
0 \\
0 \\
0 \\
z \\
n \\
z \\
z \\
0\end{array}$ & 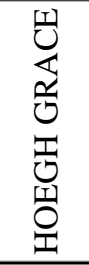 & 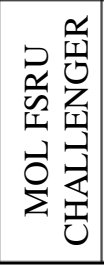 & 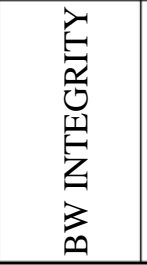 & 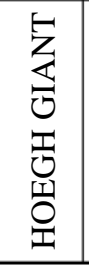 & 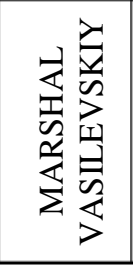 & 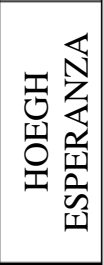 \\
\hline
\end{tabular}


Exploitation of liquefied natural gas cold energy in Floating Storage Regasification Units

Table A.1 FSRU fleet list at the end of 2020 (end)
Manuel Naveiro, Manuel Romero Gómez, Ignacio Arias Fernández, Javier Romero Gómez

\begin{tabular}{|c|c|c|c|c|c|c|c|}
\hline 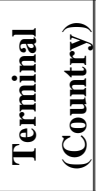 & 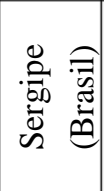 & (2) & 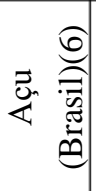 & 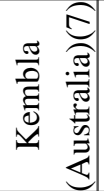 & 氧誉 & ' & 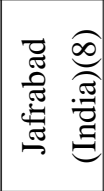 \\
\hline U & 忩 & 亥 & 忩 & 忩 & 文 & 劣 & 곡 \\
\hline 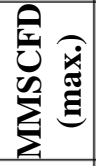 & $\stackrel{R}{n}$ & $\S$ & & $\stackrel{2}{n}$ & ' & ' & t \\
\hline 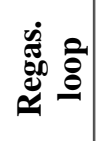 & 0 & $\underbrace{0}_{0} 0$ & 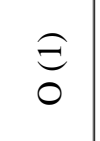 & $\underset{0}{\Xi}$ & $\underset{0}{\tilde{\theta}}$ & $\underbrace{e_{0}}_{0}$ & \\
\hline$\dot{\frac{a}{2}}$ & 窝 & 㸝 & 窐 & 窝 & 窝 & 䝁 & 䆓 \\
\hline 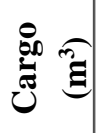 & $\begin{array}{l}8 \\
8 \\
\varrho\end{array}$ & $\begin{array}{l}8 \\
8 \\
\unrhd\end{array}$ & 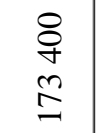 & $\begin{array}{l}8 \\
\& \\
\varrho\end{array}$ & $\begin{array}{l}8 \\
\& \\
\varrho\end{array}$ & $\underset{q}{q}$ & $\begin{array}{l}8 \\
8 \\
\infty \\
\infty\end{array}$ \\
\hline 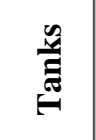 & $\begin{array}{l}\Xi \\
\text { 嵌 } \\
\sum\end{array}$ & $\begin{array}{l}\Xi \\
\text { 荘 } \\
\sum\end{array}$ & $\begin{array}{l}0 \\
8 \\
\text { Z }\end{array}$ & 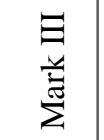 & $\begin{array}{l}\Xi \\
\Xi \\
\text { 亲 } \\
\sum\end{array}$ & 各 & 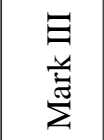 \\
\hline$\stackrel{\vec{\Xi}}{\tilde{\Xi}}$ & $i_{z}$ & z & $\stackrel{2}{z}$ & z & ż & $\stackrel{\circ}{z}$ & $\stackrel{\circ}{z}$ \\
\hline$\grave{\varpi}$ & $\stackrel{\infty}{\stackrel{\sim}{\sim}}$ & $\stackrel{\infty}{\stackrel{i}{\sim}}$ & $\stackrel{\partial}{\grave{\lambda}}$ & $\stackrel{\partial}{\partial}$ & $\stackrel{\vec{\imath}}{\grave{\lambda}}$ & ๙ิ & ๙ิ \\
\hline 㖴 & 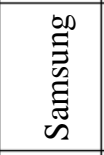 & 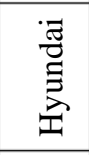 & $\begin{array}{l}8 \\
8 \\
3 \\
0 \\
0 \\
\end{array}$ & 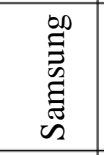 & 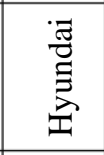 & $\begin{array}{l}8 \\
\vdots \\
\vdots \\
0 \\
0 \\
0\end{array}$ & 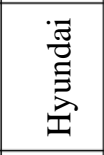 \\
\hline 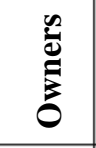 & $\begin{array}{ll}\vec{z} & \overline{0} \\
\overrightarrow{0} & 3 \\
0 & 0 \\
0\end{array}$ & 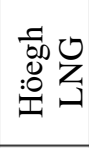 & 主 & 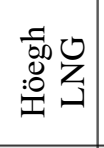 & 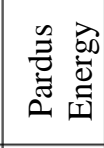 & 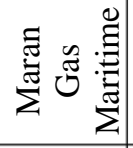 & 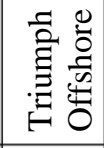 \\
\hline$\sum_{i}^{0}$ & $\begin{array}{l}8 \\
8 \\
n \\
\infty \\
\vdots \\
\vdots\end{array}$ & 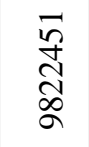 & $\begin{array}{l}\bar{a} \\
\hat{ล} \\
\text { ลิ }\end{array}$ & $\begin{array}{l}m \\
8 \\
8 \\
\infty \\
\sigma \\
\sigma\end{array}$ & $\begin{array}{l}\infty \\
\infty \\
\infty \\
\infty \\
\infty \\
\infty\end{array}$ & 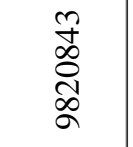 & $\begin{array}{l}\stackrel{8}{8} \\
\stackrel{2}{2} \\
\infty \\
\sigma\end{array}$ \\
\hline 芯 & 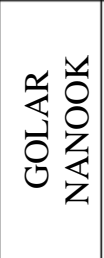 & 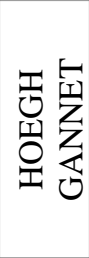 & 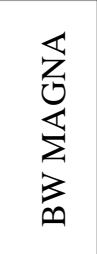 & 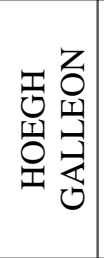 &  & 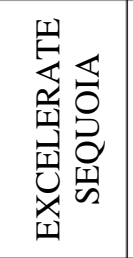 & 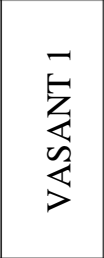 \\
\hline
\end{tabular}


Manuel Naveiro, Manuel Romero Gómez,

Ignacio Arias Fernández, Javier Romero Gómez
Exploitation of liquefied natural gas cold energy in Floating Storage Regasification Units

Notes: Closed loop (C), combined loop (CO), open loop (O). (1) Regasification loop considering the information available on the machinery. (2) Baseload capacity. (3) Normally, they operate as LNG ships. The EXEMPLAR has carried out some regasification operations in the year 2019 (Northeast Gateway). The HOEGH GIANT, according to the contract established with Naturgy, can operate as FSRU. (4) It currently operates as an LNG vessel. It will be operational in 2020. (5) Operates as FSRU and LNG vessel at intervals. (6) Installed at the end of 2019. (7) Operates as an LNG ship until construction of the terminal is completed (2021). (8) Starts operating in 2020. 
Exploitation of liquefied natural gas cold energy in Floating Storage Regasification Units
Manuel Naveiro, Manuel Romero Gómez, Ignacio Arias Fernández, Javier Romero Gómez

Table A.2 Power cycles for LNG cold energy recovery. Net power $\left(\dot{W}_{\mathrm{n}}\right)$, thermal efficiency $\left(\eta_{\mathrm{th}}\right)$, exergy efficiency $\left(\eta_{\mathrm{ex}}\right)$, economic assessment (EA)

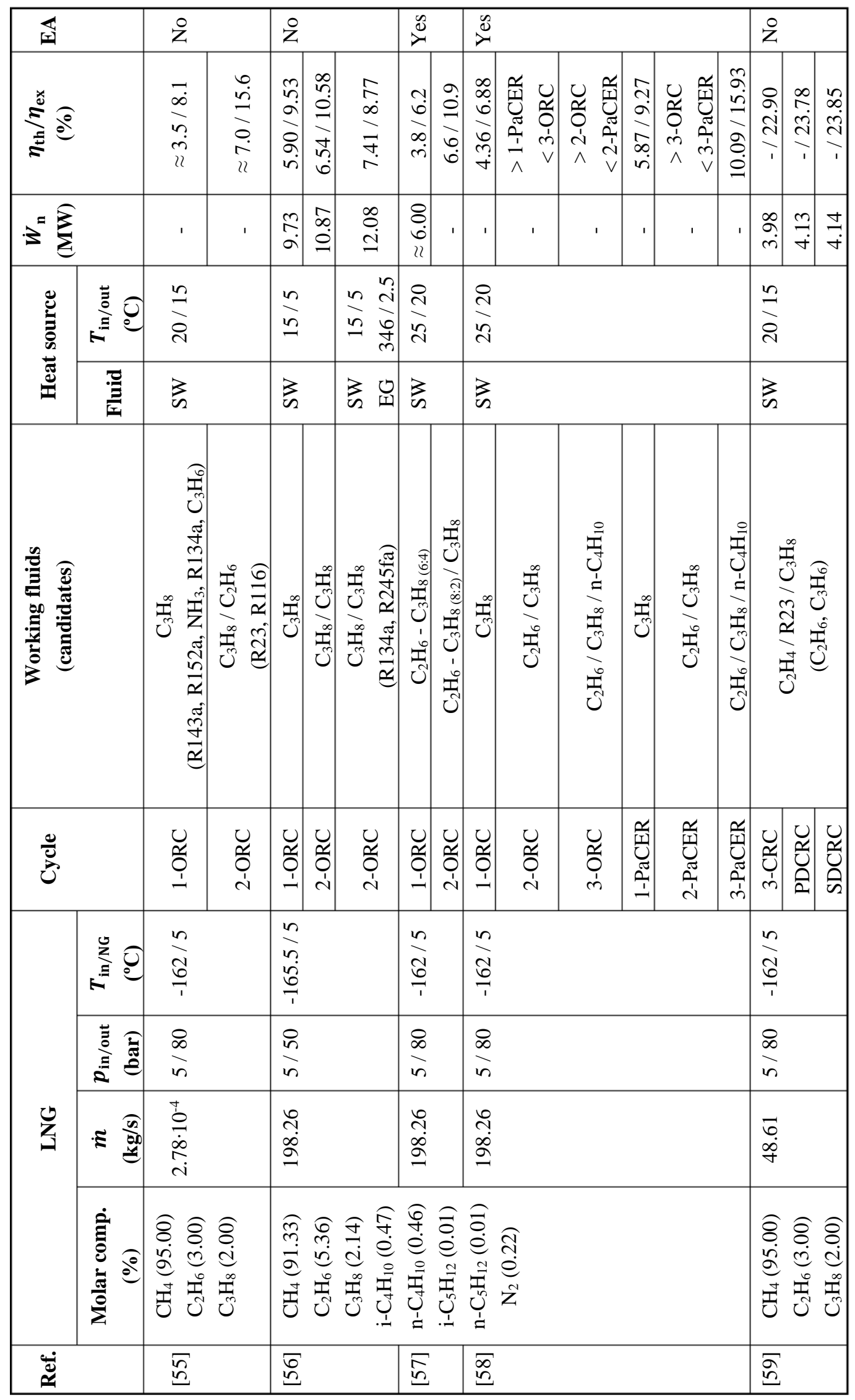


Manuel Naveiro, Manuel Romero Gómez,

Ignacio Arias Fernández, Javier Romero Gómez
Exploitation of liquefied natural gas cold energy in Floating Storage Regasification Units

Submitted: 11.10.2021. Manuel Naveiro, manuel.naveiro@udc.es 17.11.2021. ETSNM, University of A Coruña, Paseo de Ronda 51, A Coruña 15011, Spain Manuel Romero Gómez, m.romero.gomez@udc.es

Energy Engineering Research Group, University Institute of Maritime Studies, Nautical Sciences and Marine Engineering Department, ETSNM, University of A Coruña, Paseo de Ronda 51, A Coruña 15011, Spain Ignacio Arias Fernández, ignacio.arias@udc.es Energy Engineering Research Group, University Institute of Maritime Studies, Nautical Sciences and Marine Engineering Department, ETSNM, University of A Coruña, Paseo de Ronda 51, A Coruña 15011, Spain Javier Romero Gómez, j.romero.gomez@udc.es Energy Engineering Research Group, University Institute of Maritime Studies, Nautical Sciences and Marine Engineering Department, ETSNM, University of A Coruña, Paseo de Ronda 51, A Coruña 15011, Spain 